\title{
Recognition memory for object form and object location: An event-related potential study
}

\author{
A. MECKLINGER and R.-M. MEINSHAUSEN \\ Max-Planck-Institute of Cognitive Neuroscience, Leipzig, Germany
}

\begin{abstract}
In this study, the processes associated with retrieving object forms and object locations from working memory were examined with the use of simultaneously recorded event-related potential (ERP) activity. Subjects memorized object forms and their spatial locations and made either object-based or location-based recognition judgments. In Experiment 1, recognition performance was higher for object locations than for object forms. Old responses evoked more positive-going ERP activity between 0.3 and $1.8 \mathrm{sec}$ poststimulus than did new responses. The topographic distribution of these old/new effects in the P300 time interval was task specific, with object-based recognition judgments being associated with anteriorly focused effects and location-based judgments with posteriorly focused effects. Late old/new effects were dominant at right frontal recordings. Using an interference paradigm, it was shown in Experiment 2 that visual representations were used to rehearse both object forms and object locations in working memory. The results of Experiment 3 indicated that the observed differential topographic distributions of the old/new effects in the P300 time interval are unlikely to reflect differences between easy and difficult recognition judgments. More specific effects were obtained for a subgroup of subjects for which the processing characteristics during location-based judgments presumably were similar to those in Experiment 1. These data, together with those from Experiment 1, indicate that different brain areas are engaged in retrieving object forms and object locations from working memory. Further analyses support the view that retrieval of object forms relies on conceptual semantic representation, whereas retrieving object locations is based on structural representations of spatial information. The effects in the later time intervals may play a functional role in post-retrieval processing, such as recollecting information from the study episode or other processes operating on the products of the retrieval process, and presumably are mediated by right frontal cortical areas. The results support the view of functionally dissociable object and spatial visual working memory systems.
\end{abstract}

Working memory is generally conceptualized as a system that enables the representation of information in its absence, as well as the control of activation of these representations (see Posner \& Raichle, 1994). Although working memory essentially had been considered to be a unitary short-term store of limited capacity (Atkinson \& Shiffrin, 1968), recent models have assumed that different kinds of information are stored and processed independently in working memory (cf. Baddeley, 1986; Daneman \& Tardif, 1987). Baddeley's model is perhaps the most articulated working memory model in this respect and assumes two independent storage systems for phonological and visual-spatial information: a phonological loop and

Portions of these data were presented at the Thirty-Fourth Annua Meeting of the Society for Psychophysiological Research, 1994, Atlanta, and at the First International Conference on Functional Mapping of the Human Brain, 1995, Paris. We wish to thank Martin Meyer and Thomas Hälbig for data collection, Erdmut Pfeifer for his valuable support in software production, as well as Angela Friederici and Paul Gorrell for helpful comments on earlier versions of the manuscript. Correspondence concerning this article should be addressed to A. Mecklinger, Max-Planck-Institute of Cognitive Neuroscience, Inselstraße 22 04103 Leipzig, Germany (e-mail: meckling@cns.mpg.de)

-Accepted by previous editor, Geoffrey R. Loftus a visuospatial sketch pad, both of which are controlled and coordinated by a central executive component.

The notion of a unitary storage system for visual-spatial information has been challenged by neurological evidence suggesting that object properties, such as shape and color, and spatial properties, such as location or velocity, are processed in functionally and neuroanatomically different systems. The object properties pathway connects the occipital lobe with the inferior temporal lobe, and the spatial properties pathway runs from the occipital lobe to the parietal lobe. These dissociations have been inferred from selective deficits in visual discrimination tasks after damage to temporal or parietal cortical brain regions (Ungerleider \& Mishkin, 1982). Experimental lesions to the parietal lobe of monkeys selectively impair the visual discrimination of an object's spatial location, whereas, after lesions to the temporal lobe, the monkeys are unable to discriminate between object forms (for an overview, see Ungerleider \& Haxby, 1994). The two neuroanatomical systems representing object and spatial properties have been called the ventral what and the dorsal where systems, respectively (Ungerleider \& Mishkin, 1982). Recent work, however, indicates that there is a considerable degree of cross-talk among the neuronal systems mediating the identification and localization of objects (see, e.g., van Essen, Anderson, \& Felleman, 1992). Other studies 
suggest that the two systems are better characterized in terms of the output functions they subserve rather than the type of information being processed (Goodale \& Milner, 1992; see also Ingle, 1993). This latter work argues against too simplistic views of the what and where bifurcation.

The functional and neuroanatomical dissociation in the processing of object-based (what) and spatial-based (where) information in animal research is paralleled by neuropsychological studies. Patients with temporooccipital lesions have large impairments in tasks requiring the imaging of object features (e.g., parts of familiar animals) but have no difficulties in spatial tasks such as mental letter rotation (Farah, Hammond, Levine, \& Calvanio, 1988). Other patients show the reverse pattern of deficits (Farah, 1988). A similar double dissociation with neurological patients was reported by Newcombe, Ratcliff, and Damasio (1987).

Whereas the notion of dissociable systems for processing object-based and spatial-based information in the above-mentioned studies was inferred from selective deficits after experimental or clinical brain lesions, there is also evidence from studies using the dual-task interference paradigm, according to which working memory functions in intact human subjects can be segregated along these lines. With this paradigm, it is possible to examine selective interference effects that occur when the degree of interference from processes drawing on different hypothetical modules is small and interference between processes drawing on the same module is pronounced (for an overview, see Baddeley, 1990). For example, in a study by Tresch, Sinnamon, and Seamon (1993), object memory was found to be selectively impaired by a color discrimination object interference task, whereas spatial memory was selectively impaired by a movement discrimination spatial task. Similar results were reported by Baddeley and Lieberman (1980) and by Logie and Marchetti (1991).

Such selective interference effects are also compatible with the results of recent functional brain-imaging studies, which indicate that the maintenance of object information and spatial information in working memory is mediated by different brain regions. For example, E. E. Smith et al. (1995) used the positron emission tomography (PET) technique to examine brain activation during working memory operations for spatial and object information. Comparing an object and a spatial working memory task with corresponding perceptual tasks revealed pronounced right-hemisphere activity in occipital, parietal, and prefrontal areas in the spatial task, whereas left inferior temporal and parietal activation was obtained in the object task.

Analogous separations for object-based and spatialbased information at even higher levels of cognition have recently been proposed by Landau and Jackendoff (1993). Their model assumes that the functional disparity for what and where information in the visual domain is paralleled in the language domain by the way language encodes objects and places (Landau \& Jackendoff, 1993; see also Landau \& Stecker, 1990). Although this latter notion of a linguistic disparity between object and spatial properties is still controversial and requires further empirical verification (cf. Friederici, 1993), the data from dual-task interference studies and functional brain-imaging studies provide good evidence for a separation of object processing and spatial processing in visual working memory.

The major goal of the present study was to examine particular aspects of visual working memory-namely, the processes associated with the retrieval of object and spatial information from working memory - by analyzing behavioral measures and event-related potentials (ERPs). ERPs are small voltage oscillations measured at the scalp that are time-locked to the processing of externally presented events. Differences in amplitude or latency of particular ERP components can be used to make inferences about the timing and nature of stimulus processing under different experimental conditions (Hillyard \& Kutas, 1983). Moreover, the scalp topography of particular ERP components allows differentiation between the brain systems mediating particular aspects of cognitive processing (Gevins, Cutillo, \& M. E. Smith, 1995; Johnson, 1993). On the basis of their high temporal resolution (i.e., in the millisecond domain), ERPs can be used to distinguish between working memory operations, such as encoding, retention/rehearsal, or retrieval operations, by suitable separations along the time dimension. For instance, negative slow waves in the ERP during the retention interval of a working memory task have been found to be correlated with the type and amount of materials rehearsed in working memory (Ruchkin, Johnson, Grafman, Canoune, \& Ritter, 1992). Moreover, it has been argued that negative slow waves have task-specific topographies and reflect increased neuronal activity in restricted neocortical layers close to the electrode sites at which they are recorded (Birbaumer, Elbert, Canavan, \& Rockstroh, 1990; Rösler, Heil, \& Hennighausen, 1995).

ERPs associated with retrieval operations have been examined in a large variety of tasks, such as continuous recognition (Rugg, Furda, \& Lorist, 1988) and studytest designs (Mecklinger, Kramer, \& Strayer, 1992) using verbal (Karis, Fabiani, \& Donchin, 1984; Paller \& Kutas, 1992; M. E. Smith \& Halgren, 1989) and nonverbal materials (Barrett, Rugg, \& Perrett, 1988; Friedman \& Sutton, 1987). A consistent finding of these studies is that correctly recognized old stimuli evoke more positivegoing waveforms than do correctly recognized new stimuli, starting around $300 \mathrm{msec}$ poststimulus and persisting for several hundred milliseconds. This difference is commonly referred to as the old/new effect (for an overview, see Rugg, 1995). It has been proposed that the magnitude of the old/new effect is correlated with the amount of information retrieved (Rugg, Cox, Doyle, \& Wells, 1995). For example, in study-test paradigms, the magnitude of the old/new effect interacts with memory load-that is, the difference between old and new stimuli gets smaller the more information has to be retained in memory (cf. Mecklinger et al., 1992) and is virtually absent 
with large memory sets, such as eight items (cf. Mecklinger \& Müller, 1996). Old/new effects with the abovementioned temporal characteristics are not observed with stimuli that are erroneously classified as old or with old stimuli classified as new (Neville, Kutas, Chesney, \& Schmidt, 1986; M. E. Smith, 1993), indicating that especially old/new effects that onset around $300 \mathrm{msec}$ are associated with memory retrieval operations. From a functional point of view, it is assumed that the repetition of an item initiates the retrieval of a memory trace formed on its initial presentation and that this process leads to an enhanced positive ERP component (Paller \& Kutas, 1992; Paller, Kutas, \& McIsaac, 1995). In light of the above-mentioned findings, ERP old/new effects appear to be a valuable method for monitoring access and retrieval of object and spatial information from working memory.

The present experiments contrasted the retrieval of object-form information and object-location information from working memory. In order to ensure that retrieval operations can be disentangled from differences in memory organization that arise during encoding, a modified study-test procedure was employed. In this procedure, the study phases were kept identical for the object and spatial recognition tasks. However, prior to the test phases, a task cue was presented indicating whether recognition judgments for object forms or object locations would be required. Thus, performance of this task required the encoding of object forms and their respective locations, holding both features over a delay period, rehearsing only the recognition-relevant features after presentation of the task cue, and, finally, retrieving either object forms or object locations from working memory during the test phases. This procedure enables us to examine ERP activity evoked by old and new recognition judgments for object locations and object forms, using physically the same test stimuli in both recognition tasks.

In Experiment 1, processes associated with the retrieval of object forms and object locations from working memory, using performance and ERP measures, were examined. In Experiment 2, different interference tasks were interpolated between the study and the test phases in order to examine whether object forms could be more easily recoded into verbal forms than could object locations. In Experiment 3, retrieval operations for object forms and object locations were again examined, using ERP measures, with performance being on a comparable level for both recognition tasks.

\section{EXPERIMENT 1}

In Experiment 1, the subjects were required to memorize four sequentially presented abstract geometrical objects and their respective locations within a twodimensional matrix. Prior to each test phase, the subjects were informed by a briefly presented task cue whether they would have to make recognition judgments with respect to object forms or object locations. In the object task, the subjects had to decide, for each of the sequentially presented objects, whether it was one of the studied objects, irrespective of its matrix position. Analogously, in the spatial task, the subjects had to decide, for each spatial location at which an object appeared, whether it was from the previous study phase. In an attempt to minimize verbal rehearsal of the stimulus materials, a verbal interference task was interpolated between the study and the test phases. If different processes are engaged in retrieving object forms and object locations from working memory, this should be reflected by differential temporal and topographical characteristics of the old/new effects evoked by the two types of recognition judgments. Analogously, if different cortical areas are engaged in the rehearsal of object forms or object locations, we expect topographically different ERP patterns to be evoked by the task cues.

\section{Method}

\section{Subjects}

Sixteen volunteers ( 8 male) between 19 and 32 years of age (mean, 27 years) participated in this experiment. All the subjects were students. They had normal or corrected-to-normal vision, were right-handed, and were paid $12 \mathrm{DM} / \mathrm{h}$ for their participation. None of the subjects had any prior experience with the task.

\section{Stimuli}

All the stimuli were presented on a 17-in. VGA monitor under the control of a 486 computer. They consisted of the following 12 simple geometric forms: circle, cross, triangle, ellipse, rectangle, diamond, square, bend, ring, trapezoid, hexagon, and parallelogram. All the objects were presented in 1 of 12 equally spaced squares of a $4 \times 3$ grid with horizontal and vertical sidelines of 28 and $21 \mathrm{~cm}$, respectively. The height and width of each square was $7 \mathrm{~cm}$, and the average diameter of the object forms was $5.5 \mathrm{~cm}$. All the stimuli and the grid were presented in blue (RGB color, 0:0:100) against a light gray background (RGB color, 90:90:90).

\section{Procedure}

The subjects were seated comfortably in a dimly lit room in front of the monitor. They sat at a distance of about $90 \mathrm{~cm}$ from the screen and held a small response box on their laps. Each subject performed one session that included 70 study-test trials. The temporal sequence of a trial is displayed in Figure 1.

The subject started each trial by pressing a button. Next, four objects were presented sequentially at random positions within the 4 $\times 3$ spatial matrix. The subjects were instructed to memorize both the four objects and their respective spatial positions within the matrix. One second after the end of the study phase, the words "bitte warten" (please wait) were presented for $3 \mathrm{sec}$ in the center of the screen. In order to minimize verbal rehearsal of the study materials, the subjects performed an articulatory suppression task between the study and the test phase - that is, they were instructed to repeat aloud the word "Pfau" three times upon presentation of the words "bitte warten." Similar articulatory suppression tasks have been shown to prevent subjects from verbally recoding visual stimuli (cf. Baddeley, 1986). Next, one of two task cues was presented, indicating that either an object or a spatial recognition memory task had to be performed. The task cues were the three-letter strings OBJ and POS for the object and spatial task, respectively. In the spatial task, the subjects were required to indicate for each of the eight consecutive recognition stimuli whether or not one of the positions from the study list, irrespective of the object form, was presented. In the object task, the subject indicated whether or not one of the study list objects was presented, irrespective of its spatial position. In both 


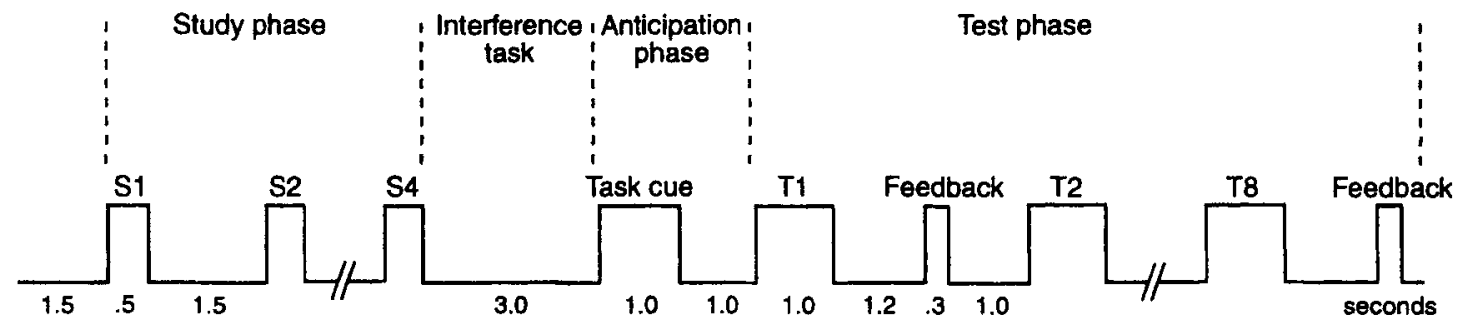

Figure 1. Schematic illustration of the temporal sequence of stimulus presentation within an experimental trial. S1 to S4 indicate the four study stimuli, T1 to T8 the eight test stimuli.

tasks, the subjects pressed one button to respond old and another button to respond new with either the left or the right hand, respectively. There were four old and four new stimuli within each test phase. After each response, feedback was provided (correct, false, or no response). In the object recognition task, two of the four old (new) objects were presented at positions that also occurred in the study phase; the other two old (new) objects were presented at unstudied positions. However, old objects were never presented at exactly the same spatial positions as they were during study. The same constraints were applied in the spatial recognition task.

Task order within the 70 trials was randomized, and both tasks were presented with the same probability (i.e., 50\%). The study and test items were presented with the restriction that spatial positions in the left and right half of the grid were equiprobable. The assignment of response hand to response button was counterbalanced across subjects. The subjects were instructed to memorize both the objects and their respective spatial locations during study and to preserve a visual image of the objects and their locations. They were also informed that, in $50 \%$ of the trials, they would have to recognize object locations, and, in the other $50 \%$ of the trials, they would have to recognize object forms. They were told to respond as quickly and as accurately as possible. Six practice trials were given to the subjects at the beginning of the session. Including electrode application and removal, each session lasted about $1^{1 / 2} \mathrm{~h}$.

\section{ERP Recording}

The EEG activity was recorded from 20 scalp electrode sites of the 10-20 system, using tin electrodes mounted in an elastic cap (Electrocap International). The ground electrode was positioned $10 \%$ of the nasion-inion distance anterior to $\mathrm{Fz}$. The vertical electrooculogram (EOG) was recorded from 2 electrodes located above and below the right eye. The horizontal EOG was recorded from 2 electrodes positioned at the outer canthus of each eye. Electrode impedance was kept below $5 \mathrm{k} \Omega$. All of the 20 scalp electrodes were referenced to the left mastoid. The EEG and EOG channels were recorded continuously with a bandpass from $\mathrm{DC}$ to $70 \mathrm{~Hz}$ and were $A / D$ converted with 16 -bit resolution at a sampling rate of $250 \mathrm{~Hz}$. In order to determine whether there were any effects of the experimental variables on the mastoid recordings, the right mastoid was actively recorded as 1 of the 20 channels. No such effects were observed in any of the data; therefore, the right mastoid channel was not included in the statistical analyses.

\section{Data Analysis}

Behavioral data. Reaction time was defined as the interval between the appearance of the recognition items and the subject's keypress. All of the reaction time averages were composed of correct responses only.

ERP data. ERPs time-locked to the onset of the cues and the test items were computed for each subject at all recording sites, with epochs extending from $0.2 \mathrm{sec}$ before stimulus onset until $2 \mathrm{sec}$ thereafter. The ERPs evoked by the test stimuli were selectively averaged for old and new responses. In order to establish a correspon- dence between performance measures and ERP measures, only stimuli containing correct responses were entered in these subject averages. The average voltage in the $0.2 \mathrm{sec}$ preceding the items was examined for systematic differences as a function of experimental condition. Because no systematic effects were found, this epoch served as a baseline-that is, its mean value was subtracted from each data point in the waveforms. Prior to averaging, each epoch was scanned for EOG and other artifacts. Whenever the standard deviation $(S D)$ in a 0.2 -sec time interval exceeded $50 \mu \mathrm{V}$, the epoch was rejected.

ERPs to the task cues and to the test items were quantified as mean amplitudes in three consecutive time intervals. In order to reduce the risk of Type I errors that is inherent in the statistical analysis of multielectrode and multicomponent data (cf. Oken \& Chiappa, 1986), global multivariate analyses of variance (MANOVAs), with response type (or task), electrode, and time interval as factors, were performed for an overall test of the effects of the response type or task factors. In case of significant main effects of the response type or task factors or interactions involving these factors, repeated measures analyses of variance (ANOVAs) were used to evaluate the effects of these factors separately for the time intervals. All effects with two or more degrees of freedom in the numerator were adjusted for violations of sphericity, according to the formula of Geisser and Greenhouse (1959). If not specified otherwise, post hoc comparisons were performed by means of a modified Bonferroni procedure (Keppel, 1991).

\section{Behavioral Data}

\section{Results}

The top part of Table 1 shows mean reaction times, proportions of correct old and new responses, and the corrected recognition scores (CR; i.e., hit rate minus false alarm rate) for both memory tasks. As is apparent from Table 1, the pattern of corrected recognition scores is consistent with that of the proportion of correct old and new responses. For reasons of simplicity and consistency with the ERP analyses, we only present the analyses for the latter measures. ' The subjects responded more quickly and more accurately to object locations than to object forms. Moreover, for both tasks, old responses were faster than new responses and also slightly less accurate. Twoway repeated measures ANOVAs, with task (object vs. spatial) and response type (old vs. new) as factors, revealed main effects of task $[F(1,15)=70.00, p<.001]$ and response type $[F(1,15)=32.37, p<.001]$ for reaction times. For performance accuracy, a main effect of task $[F(1,15)=50.49, p<.001]$ and a marginally significant effect of response type $[F(1,15)=4.12, p<.06]$ were obtained. ${ }^{2}$ 
Table 1

Performance Results (With Standard Errors) in the Object and the Spatial Memory Tasks of Experiment 1 and Experiment 3

\begin{tabular}{|c|c|c|c|c|c|c|c|c|c|c|}
\hline \multirow[b]{2}{*}{ Task } & \multicolumn{4}{|c|}{ Reaction Time (msec) } & \multicolumn{4}{|c|}{$\%$ correct } & \multirow[b]{2}{*}{$\mathrm{CR}$} & \multirow[b]{2}{*}{$S E$} \\
\hline & Old & $S E$ & New & $S E$ & Old & $S E$ & New & $S E$ & & \\
\hline \multicolumn{11}{|c|}{ Experiment 1} \\
\hline Object memory & 781 & 36 & 823 & 35 & 76.8 & 2.1 & 78.3 & 2.6 & 55.1 & 4.1 \\
\hline Spatial memory & 662 & 32 & 702 & 28 & 84.1 & 2.5 & 90.2 & 1.7 & 74.3 & 3.8 \\
\hline \multicolumn{11}{|c|}{ Experiment 3} \\
\hline Object memory & 775 & 42 & 832 & 41 & 81.6 & 1.9 & 80.2 & 2.4 & 61.8 & 3.8 \\
\hline Spatial memory & 789 & 47 & 836 & 48 & 83.3 & 2.9 & 84.4 & 2.1 & 67.7 & 4.6 \\
\hline
\end{tabular}

Note $-\mathrm{CR}$, corrected recognition, difference between hit rate and false alarm rate

\section{Event-Related Potentials}

Anticipation phase. Figure 2 displays the ERP waveforms evoked by the task cue indicating either the object or the spatial memory task. The cues evoked pronounced parietal maximal P300 components, peaking at about $500 \mathrm{msec} \cdot{ }^{3}$ Differences between the object and the spatial tasks emerged at about $0.7 \mathrm{sec}$ after stimulus onset and extended until the end of the recording epoch. These differences took the form of a frontally more negative slow wave for the object task and a more pronounced negative slow wave at the parietal and the occipital recordings for the spatial task. Visual inspection of Figure 2 further suggests that the between-task differences had an earlier onset and a shorter duration at the frontal than at the parietal-occipital electrodes and that they were larger at the right than at the left posterior recordings. On the basis of these observations, five successive time intervals of 250 -msec duration in the 0.75 - to 2-sec portion of the waveforms were used for quantification of the ERP data. The global MANOVA, with task ( 2 levels), electrode (19 levels), and time interval ( 5 levels) as factors, revealed a main effect of time interval $[F(4,60)=6.15, p<.009]$ and interactions of task and electrode $[F(18,270)=$ $3.76, p<.004]$ and of task, time interval, and electrode $[F(72,1080)=1.65, p<.001]$. The results of the ANOVAs for each time interval are displayed in the top part of Table 2 . For the time intervals $1-1.25,1.25-1.5$, and 1.75 $2.0 \mathrm{sec}$, significant task $\times$ electrode interactions were obtained, whereas this interaction was marginally significant in the $0.75-1$ and $1.5-1.75 \mathrm{sec}$ time intervals.

In order to examine the time course and the scalp topography of these effects in more detail, ANOVAs, with task as factor, were performed separately for frontal $(\mathrm{F} 3, \mathrm{Fz}$, and F4) and parietal-occipital electrodes ( $\mathrm{P} 3, \mathrm{Pz}, \mathrm{P} 4, \mathrm{O} 1$, and $\mathrm{O} 2$ ). These analyses revealed significant effects of task at the frontal electrodes in the time intervals from .75 to $1.5 \mathrm{sec}(p \mathrm{~s}<.05)$. At the posterior electrodes, the waveforms were significantly more negative in the spatial than in the object task in the four time intervals from 1 to $2 \sec (p s<.03)$. This pattern of results confirms the later onset and longer duration of the posterior negative slow wave in the spatial task. Lateralization of the posterior slow wave pattern in the spatial task was assessed by means of post hoc comparisons for pairs of lateral electrodes - that is, P3-P4 and O1-O2. However, no reliable hemispherical differences in slow wave amplitude were obtained $(p s>.20)$.

Old/new effects for object forms and object locations. The ERP waveforms evoked by old and new items in the test phases of the spatial and the object recognition tasks are presented in Figures 3 and 4. In both tasks, a posterior negative component with a peak latency of $168 \mathrm{msec}(\mathrm{Pz})$ and an anteriorly distributed positive component peaking at $230 \mathrm{msec}(\mathrm{Fz})$ were obtained. These two components will be referred to as N100 and P200, respectively. The offset of the test stimuli at $1 \mathrm{sec}$ in both tasks elicited low-amplitude ERP deflections around $1.2 \mathrm{sec}$. Larger positivities for old than for new stimuli were evident with a wide temporal and topographical distribution. In both tasks, these old/new differences ranged from $0.3 \mathrm{sec}$ to the end of the recording epoch. On the basis of this observation, old/new effects were examined separately in three consecutive time intervals: $0.3-0.6,0.7-1.1$, and $1.2-1.8 \mathrm{sec}$. These intervals will be referred to as early, middle, and late time intervals.

In the early time interval, P300 components with a central-parietal maximum scalp distribution were evoked in both tasks that were slightly delayed in amplitude for the two new conditions, as compared with the old conditions. In this time interval, amplitude differences between old and new trials were most pronounced at the anterior electrodes in the object task and at the parietal-occipital electrodes in the spatial task. This topographical dissociation of the old/new differences was also evident in the later time regions and extended to the end of the recording epoch. However, an exception to this anterior/posterior dissociation was obtained in the $0.7-1.1 \mathrm{sec}$ time interval. In this period, a substantial old/new effect emerged for the spatial memory task at the right frontal (i.e., F4) and central (i.e., C4) electrodes. Moreover, right lateralization of the old/new differences (i.e., larger differences at the right- than at the corresponding left-hemisphere electrodes) in the later time intervals was apparent at those electrodes where they were largest-for example, at the frontal electrodes in the object task and at the parietal electrodes in the spatial task.

These observations were confirmed by a series of statistical analyses. ${ }^{4}$ The results of the two-way ANOVAs 
Anticipation phase

\section{Object task Spatial task}
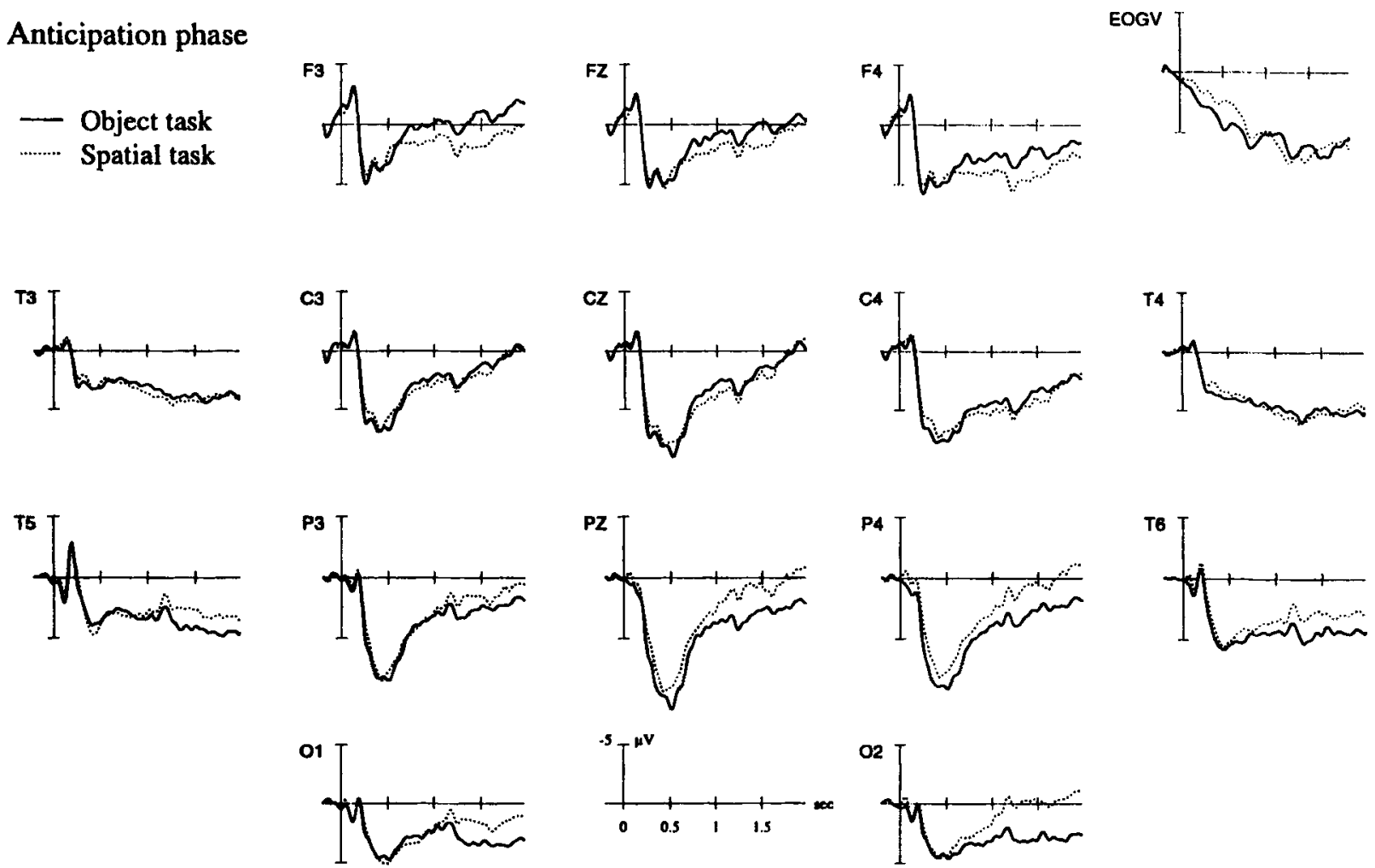

Figure 2. ERP waveforms, averaged across subjects, elicited by the task cues indicating the object or the spatial recognition memory task of Experiment 1. Note that, for reasons of perspicuity, only 15 of the 19 electrodes entered in statistical analyses are displayed in this and the following figures. The vertical lines indicate the onset of the cues that were presented with a duration of 1,000 msec. The layout of the figure roughly corresponds to the layout of the electrodes on the head, with the top of the figure corresponding to the top of the head. The vertical electro-oculogram (EOGV) is plotted in the upper right corner of the figure.

performed separately for each time interval in both tasks are displayed in the top part of Table 3. For both tasks, significant main effects of response type and interactions of response type and electrode were obtained in all three time intervals.

In order to further examine the latter interactions, ANOVAs with response type as factor were conducted for electrodes over the mid-frontal (F3, Fz, and F4) and parietal-occipital regions $(\mathrm{P} 3, \mathrm{Pz}, \mathrm{P} 4, \mathrm{O1}$, and $\mathrm{O} 2)$ in both tasks. These analyses revealed highly significant old/new effects in the three time intervals for the object task at the frontal recordings $(p s<.001)$. Over the parietal-occipital region, these effects did not reach the significance level ( $p s>.08)$. A different pattern of results was obtained for the spatial task: Highly reliable old/new effects were observed over the parietal-occipital region $(p s<.002)$. At the frontal regions, no reliable old/new effects in the early and the late intervals were found ( $p s>$ $.10)$. However, in the middle time interval at the frontal recordings, the ERPs elicited by old spatial locations were

Table 2

ANOVA Results (in Seconds) for the Time Intervals in the Anticipation Phases in Experiment 1 and Experiment 3

\begin{tabular}{|c|c|c|c|c|c|c|}
\hline \multirow[b]{2}{*}{ Source } & \multicolumn{6}{|c|}{$F$} \\
\hline & $d f$ & $0.75-1$ & $1-1.25$ & $1.25-1.5$ & $1.5-1.75$ & $1.75-2.0$ \\
\hline \multicolumn{7}{|c|}{ Experiment 1} \\
\hline Task & 1,15 & 0.29 & 0.00 & 0.16 & 0.28 & 1.01 \\
\hline Electrode & 18,270 & $2.96 \dagger$ & $3.14 t$ & $2.12^{*}$ & $2.09^{*}$ & $2.60_{+}^{+}$ \\
\hline Task $\times$ electrode & 18,270 & $2.07^{*}$ & $4.68 t$ & $5.53 \%$ & $2.19^{*}$ & $2.91 \dagger$ \\
\hline \multicolumn{7}{|c|}{ Experiment 3} \\
\hline Task & 1,17 & 2.00 & $4.47 \dagger$ & $3.13^{*}$ & $3.26^{*}$ & $3.41^{*}$ \\
\hline Electrode & 18,306 & $2.69 \dagger$ & $5.25_{t}^{+}$ & $3.82 \ddagger$ & $2.73 \ddagger$ & $3.70_{\ddagger}^{\dagger}$ \\
\hline Task $\times$ electrode & 18,306 & 1.21 & $1.53^{\mathrm{T}}$ & $2.55 \dagger$ & $2.56 t$ & $1.92^{*}$ \\
\hline
\end{tabular}


Test phase: Object memory

$$
\begin{array}{cc}
- & \text { Old } \\
\ldots . . . . . & \text { New }
\end{array}
$$
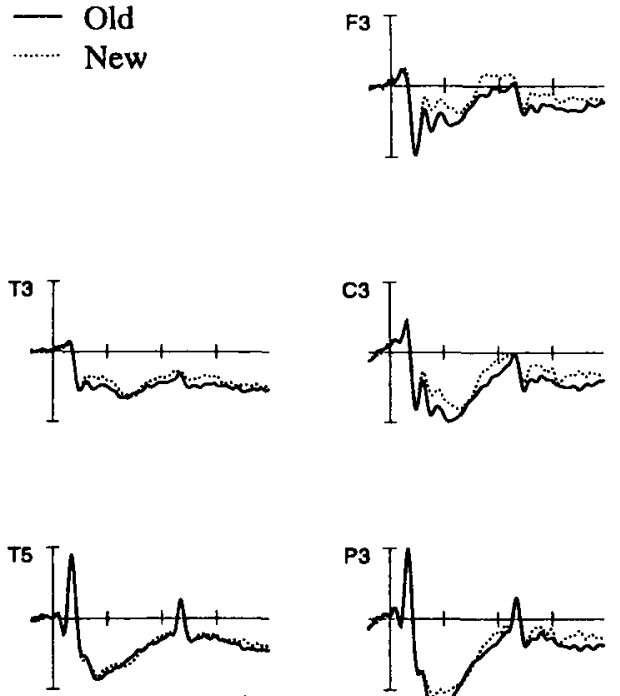
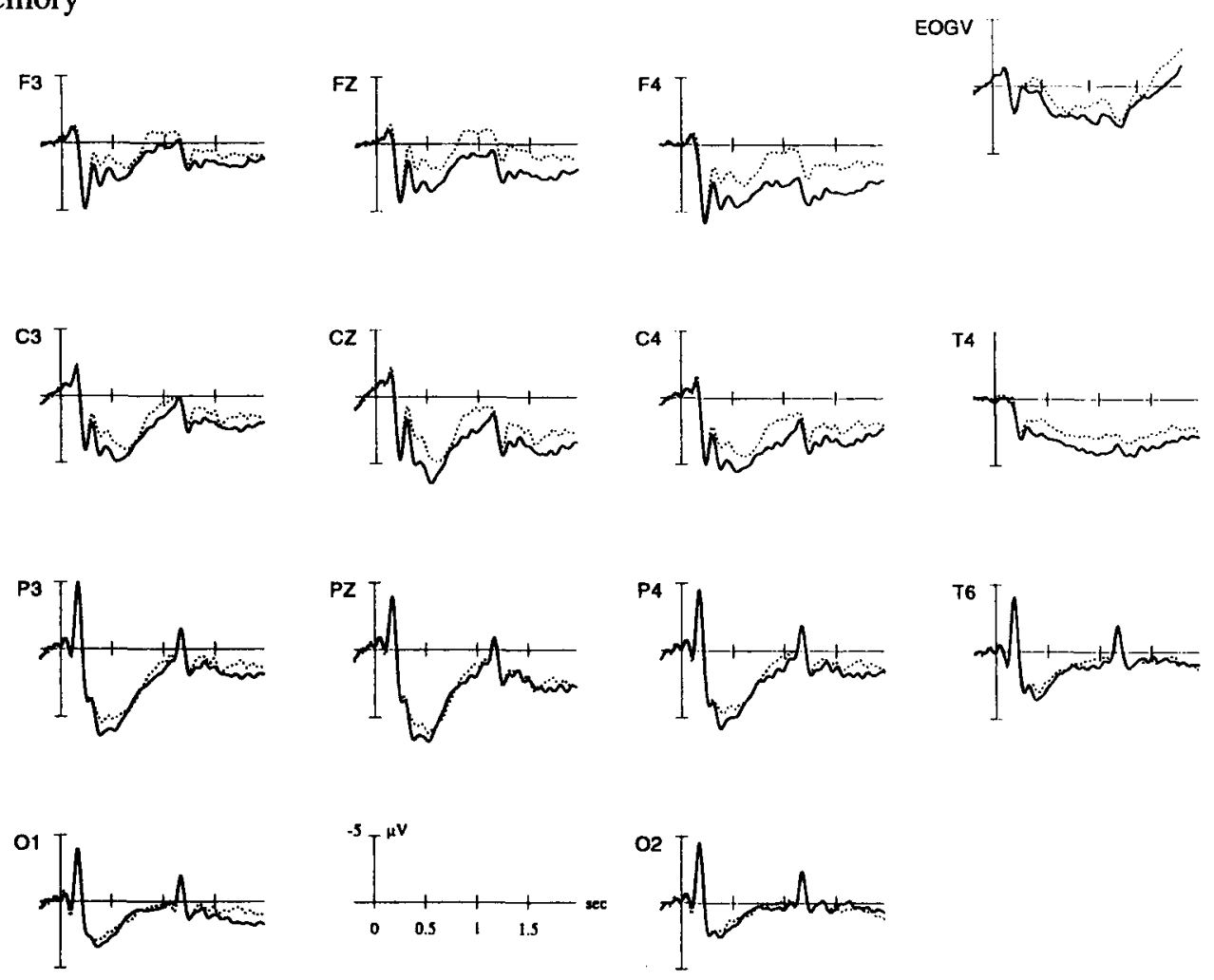

Figure 3. ERP waveforms, averaged across subjects, elicited by old and new responses in the test phase of the object recognition memory task of Experiment 1.

more positive than those evoked by new spatial locations $(p<.02)$. This differential pattern of results is further illustrated in Figure 5, displaying the estimated effect strength ( $\omega^{2} ;$ cf. Keppel, 1991; see also Richardson, 1996) in the three time intervals. ${ }^{5}$

Lateralization of the old/new differences was examined by means of pairwise comparisons among pairs of lateral electrodes. The following picture emerged: In the early time interval, significantly larger right-hemisphere effects were found for the spatial task at the posterior temporal electrodes (i.e., T5 vs. T6; $p<.005$ ), and marginally significant effects were found at the parietal electrodes (i.e., P3 vs. P4; $p<.055$ ). In the middle time interval, right lateralization in the spatial task was evident at the parietal and the frontal electrodes $(p s<.02)$. At the frontal electrodes, this right lateralization extended to the late time interval $(p<.002)$. For the object task, right lateralization of the old/new differences was only obtained at the frontal electrodes (F3 and F4) in the middle and late time intervals $(p s<.01)$. Further analyses, performed separately for the waveforms evoked by old and new responses, indicated that, in the late time interval, the waveforms evoked by old objects were more positive at the right than at the left frontal recordings $(p<.01)$, whereas, for the waveforms evoked by new responses, no hemispherical differences were obtained $(p>.17)$.
Topographical analyses. The topographical differences of the old/new effects in the object and the spatial memory tasks might suggest that the effects arise from different combinations of neuronal sources. In fact, twoway ANOVAs, with task and electrode as factors, performed for the difference between old and new responses were significant in the early $[F(18,270)=3.99, p<.02]$, middle $[F(18,270)=7.86, p<.001]$, and late time intervals $[F(18,270)=7.87, p<.0001]$. To ensure that the topographic comparison between the old/new effects in both tasks is not confounded with between-task differences in absolute amplitude (see Johnson, 1993), the data were normalized so that the RMS amplitudes of the old/new differences (averaged across subjects) were the same for the two tasks (McCarthy \& Wood, 1985). Reliable interactions of task and electrode were found for the normalized old/new differences in all three time intervals ( $p s<.02)$, suggesting that different neuronal generators contributed to the old/new differences in the object and the spatial memory tasks. ${ }^{6}$

Separate analyses for old and new responses. In light of the task-specific topographic distribution of the old/new effects, between-task comparisons were also performed separately for the old and new waveforms in the early time interval. If the task-specific topographies of the old/new effects arise from modulations of the wave- 
Test phase: Spatial memory
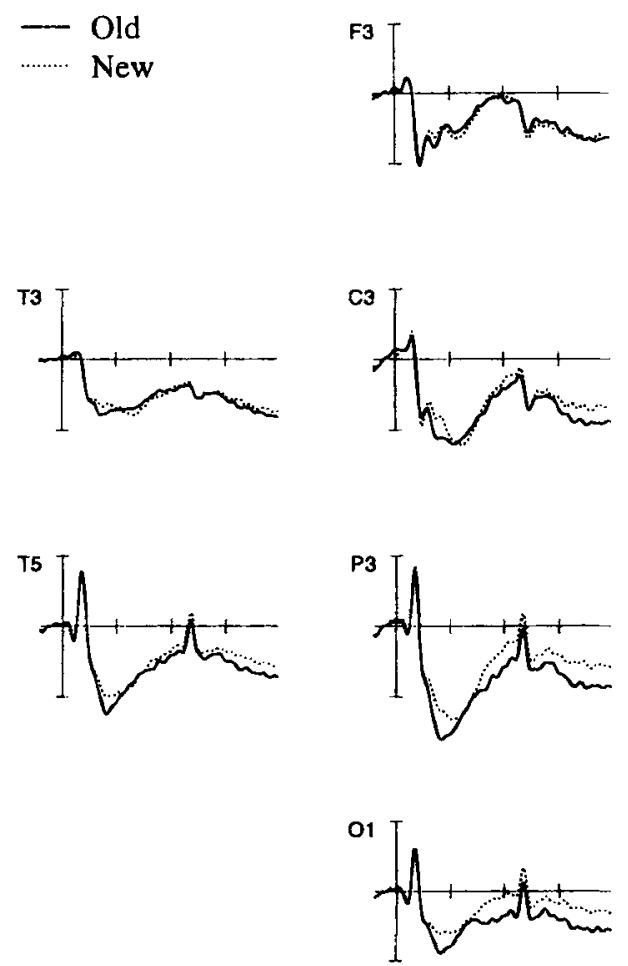
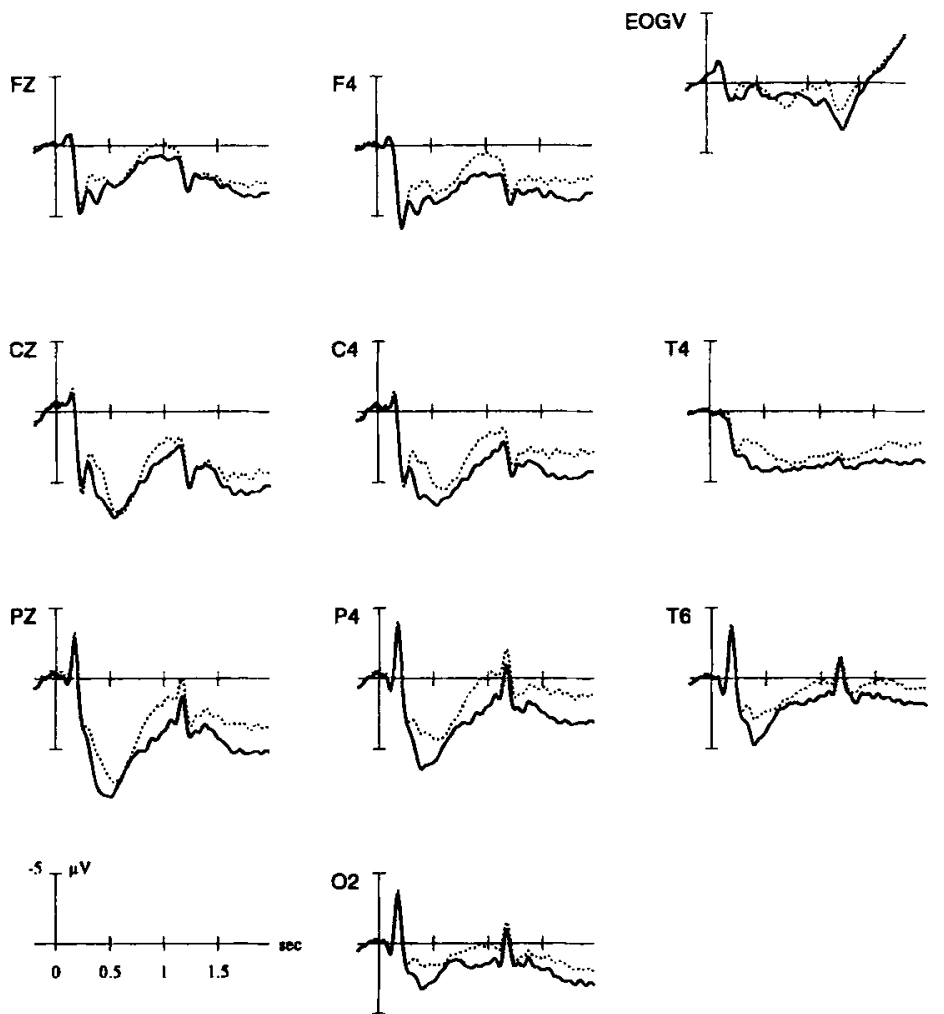

Figure 4. ERP waveforms, averaged across subjects, elicited by old and new responses in the test phase of the spatial recognition memory task of Experiment 1.

forms evoked by old responses, this should be reflected by a significant task $\times$ electrode interaction solely for this response type. In contrast, if the differential topographic distributions of the old/new effects reflect task-specific modulations of both the old and new responses, this should be evidenced by task $X$ electrode interactions for both response types. To address this issue, ANOVAs, with task and electrode as factors, were conducted for the mean amplitude measures at the three midline electrodes in the early time interval of the waveforms.

As is apparent from Table 4, which shows the mean amplitude measures for both response types, there was a task $\times$ electrode interaction for the waveforms evoked by old responses $[F(2,30)=4.36, p<.03]$. This interaction indicates that old responses to locations evoked more positive-going waveforms at the central and parietal recordings but not at the frontal recording. For the waveforms evoked by new responses, there was a task $\times$ electrode interaction as well $[F(2,30)=4.74, p<.02]$, reflecting the fact that, for new responses, the amplitude measures were smaller (i.e., more negative) for objects at the frontal and central recordings but to a much lesser extent at the parietal recording. These results indicate that the old/new effects in the early time interval reflect task- specific modulations of the old and new waveforms rather than only modulations of the old waveforms.

\section{Discussion}

In Experiment 1, performance measures and ERP activity during object-based and location-based recognition judgments were examined. The faster reaction times and lower error rates obtained for the spatial recognition task suggest that object locations could be more readily accessed and retrieved from working memory than could object forms. The observation of longer reaction times and slightly higher error rates for new than for old responses is consistent with the results of other studies examining recognition judgments with study-test procedures in which a list of studied items had to be held in memory (cf. Eriksen, Eriksen, \& Hoffman, 1986; Kramer $\&$ Strayer, 1988) and suggests more extensive memory search operations for new than for old items, with this differential effect being highly similar for the two recognition tasks.

In the anticipation phases, reliable topographic and temporal ERP differences were found as a function of whether object-based or location-based recognition judgments were anticipated. This dissociation took the form 
Table 3

ANOVA Results (in Seconds) for the Three Time Intervals in the Recognition Phases of the Spatial and Object Recognition Tasks in Experiment 1 and Experiment 3

\begin{tabular}{|c|c|c|c|c|}
\hline \multirow[b]{2}{*}{ Source } & \multicolumn{4}{|c|}{$F$} \\
\hline & $d f$ & $0.3-0.6$ & $0.7-1.1$ & $1.2-1.8$ \\
\hline \multicolumn{5}{|c|}{ Experiment 1} \\
\hline \multicolumn{5}{|l|}{ Object memory } \\
\hline Response type & 1,15 & $13.62 \ddagger$ & $6.89 \ddagger$ & $6.99 \ddagger$ \\
\hline Electrode & 18,270 & $4.54+$ & $3.01 \dagger$ & $2.77 \dagger$ \\
\hline Response type $\times$ electrode & 18,270 & $2.51 \dagger$ & $4.45+$ & $4.36+$ \\
\hline \multicolumn{5}{|l|}{ Spatial memory } \\
\hline Response type & 1,15 & $19.18 \div$ & $12.50_{\ddagger}^{+}$ & $4.62 \dagger$ \\
\hline Electrode & 18,270 & $6.68 \div$ & $3.62+$ & $2.55+$ \\
\hline Response type $\times$ electrode & 18,270 & $3.58 \dagger$ & $4.36 \ddagger$ & $3.70 \ddagger$ \\
\hline \multicolumn{5}{|c|}{ Experiment 3} \\
\hline \multicolumn{5}{|l|}{ Object memory } \\
\hline Response type & 1,17 & $11.13+$ & $2.78^{*}$ & $4.54 \dagger$ \\
\hline Electrode & 18,306 & $5.17_{+}^{+}$ & $6.39 \ddagger$ & $3.85 t$ \\
\hline Response type $\times$ electrode & 18,306 & $2.29 \dagger$ & $4.02 \ddagger$ & $2.97 \ddagger$ \\
\hline \multicolumn{5}{|l|}{ Spatial memory } \\
\hline Response type & 1,17 & $5.39+$ & 1.08 & 2.28 \\
\hline Electrode & 18,306 & $2.86+$ & $5.58 \div$ & $3.03+$ \\
\hline Response type $\times$ electrode & 18,306 & $1.91^{*}$ & 0.89 & 1.37 \\
\hline
\end{tabular}

Note-The early time interval in the modified spatial memory task in Experiment 3 was 0.3 to 0.45 sec. ${ }^{*} p<.10 .{ }^{+} p<.05 .{ }^{\dagger} p<.01$.

of more pronounced negative slow wave activity at the frontal electrode sites for the object task cue and more pronounced negative slow wave activity at the parietaloccipital electrodes for the spatial task cues. It must be noted, however, that, from the present data, it cannot unambiguously be decided whether the differences in slow wave activity at the frontal and parietal-occipital recordings reflect more negative-going activity in either task or, equally likely, more positive-going activity in the other task. For example, the pronounced between-task differences at the parietal-occipital recording could also result from more pronounced positive-going ERP activity at these recordings in the object task. However, there are topographical, temporal, and functional similarities of the present slow wave pattern with those observed in other studies that shed some light on this ambiguity. For example, in a study by Heil, Rösler, and Hennighausen (1996), subjects were required to learn associations between line drawings and two-dimensional spatial configurations. Negative slow wave activity at parietal electrodes was increased in a period in which subjects anticipated the repetition of to-be-associated spatial information. Similar parietal focused negative slow waves have been reported in tasks requiring the maintenance of spatial materials in working memory (Mecklinger \& Pfeifer, 1996; Ruchkin et al., 1992). In these latter studies, negative slow waves increased with the amount of spatial information held in working memory at around $0.8 \mathrm{sec}$ after stimulus onset. These result suggests that parietal negative slow wave activity is functionally correlated with the reactivation or rehearsal of spatial information in working memory, and, given this, we are tempted to interpret the parietal- occipital ERP differences in the anticipation phase of the present experiment as a relative increase of negative slow waves associated with spatial rehearsal operations.

Differences in scalp distribution were also obtained for the old/new effects in both recognition tasks. In the object task, old/new differences were most pronounced at frontal electrodes and virtually absent at the parietaloccipital recording sites in all three time intervals. In the later two time intervals, the effects were lateralized to the right frontal recordings. In contrast, in the spatial memory task, old/new effects were evident at parietal and occipital electrodes in all three time intervals. These data suggest that retrieving object forms and retrieving object locations are associated with different brain systems.

Besides this anterior/posterior dissociation in the magnitude of the old/new effects that was already evident in the $0.3-0.6 \mathrm{sec}$ time interval, starting at $0.7 \mathrm{sec}$ for both tasks, pronounced old/new effects emerged at the right frontal recordings. Although no other signs of lateralization were obtained in the object task, a right-hemisphere dominance of spatial old/new effects was also found at the posterior temporal recordings, extending throughout the three time intervals. In view of the timing and scalp topography of these late old/new effects, it is reasonable to assume that they reflect processes that operate on the products of the retrieval process and that these processes are mediated by right-hemisphere brain areas.

Prior to discussing these results with respect to differential operations engaged in the retrieval of object forms and object locations, alternative interpretations have to be considered. First, on the basis of error rates, which amounted to $22 \%$ in the object task, it could be argued that the tasks exceeded working memory capacity and, thus, are not appropriate for the examination of retrieval from working memory. To address this issue, we contrasted the ERP data for two groups of 4 subjects each that showed the highest and lowest corrected recognition performance in the object task. For this analysis, the old/new effects were measured in the early time interval at the mid-frontal $(\mathrm{Fz})$ and the mid-parietal electrode $(\mathrm{Pz})$. For the 4 subjects with the highest performance (mean CR, 0.71), the magnitude of the old/new effects in the object task was larger at $\mathrm{Fz}(2.12 \mu \mathrm{V})$ than at $\mathrm{Pz}(1.22 \mu \mathrm{V})$. For the subjects with the lowest performance (mean CR, 0.38), a highly similar topographic distribution was obtained (Fz, $1.46 \mu \mathrm{V} ; \mathrm{Pz}, 0.44 \mu \mathrm{V})$. For the spatial task, the old/new differences for the high-recognition group were smaller at $\mathrm{Fz}(0.42 \mu \mathrm{V})$ than at $\mathrm{Pz}(1.52 \mu \mathrm{V})$. The same was true for the low-recognition group ( $\mathrm{Fz}, 0.10 \mu \mathrm{V} ; \mathrm{Pz}, 0.88 \mu \mathrm{V})$. This highly similar task-specific topographic distribution of the old/new effects for both groups suggests that the old/new effects are not confounded with high proportions of errors and, thus, can be considered appropriate measures of information retrieval from working memory.

A second concern might be that, although we attempted to minimize verbal rehearsal strategies by interpolating a verbal interference task (i.e., articulatory suppression) between the study and the test phases, it is still conceiv- 


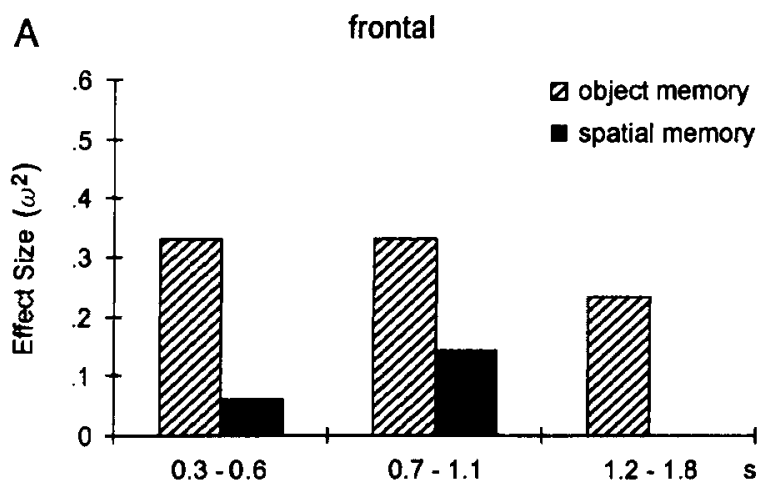

parietal - occipital

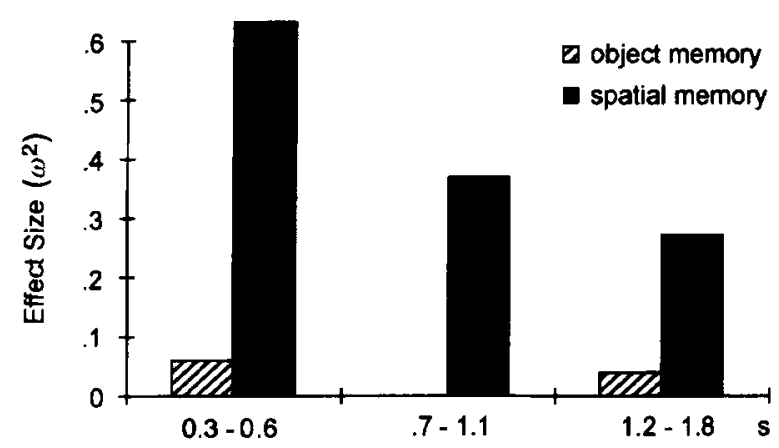

B frontal

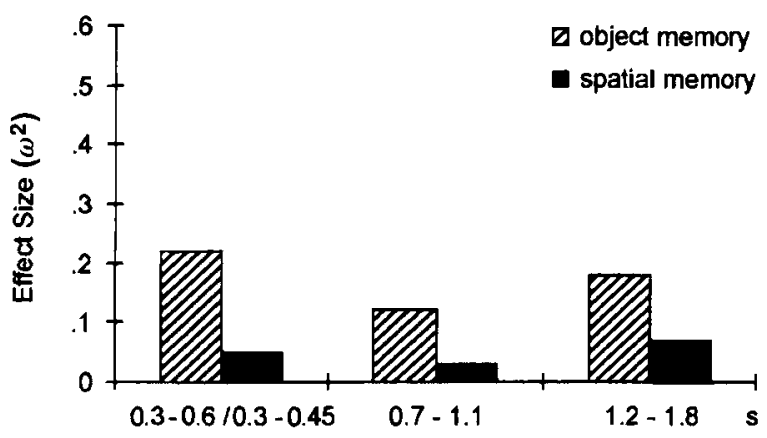

parietal - occipital

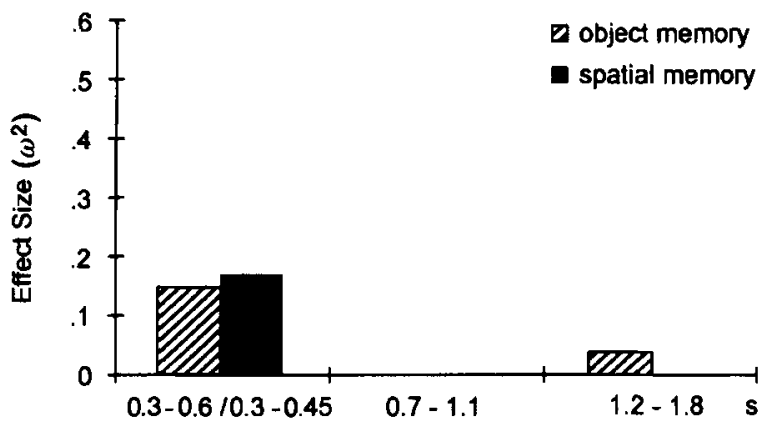

Figure 5. Strength of effect $\left(\omega^{2}\right)$ of the response type manipulations in both recognition tasks at the frontal (F3, Fz, and F4) and parietal-occipital (P3, Pz, P4, O1, and 02) electrodes in Experiment 1 (A) and Experiment 3 (B). Note that, in Experiment 3, the early time interval in the spatial task was set to $0.3-0.45 \mathrm{sec}$.

able that the object forms brought to mind their verbal descriptions and were rehearsed in verbal formats during the interference task. On the other hand, the object locations, being more difficult to be verbally recoded, might have been rehearsed in visual formats. The notion that object forms but not object locations were rehearsed in verbal formats might explain the differential performance results: Object names could be more vulnerable to the articulatory suppression task, leading to a differential disruption of object recognition performance. However, and even more important, on the basis of the latter view, it is also conceivable that the between-task differences in scalp topography of the old/new effects reflect differences between retrieving verbal and nonverbal information from memory, rather than differences in retrieving object forms and object locations.

\section{EXPERIMENT 2}

In Experiment 2, the question of whether object forms were more likely than object locations to be recoded into verbal forms was examined. To address this issue, different interference tasks were interpolated between the study and the test phases of the object and the spatial recognition tasks, and their disruptive effects on both types of recognition judgments were examined. We assumed that, if verbal labels were used to rehearse object forms and visual rather than verbal representations were used to rehearse object locations, recognition performance for both types of information should be differentially disrupted by a verbal and a visual interference task. In contrast, if both types of information are rehearsed in visual formats, performance in both tasks should be similarly disrupted by a visual interference task.

Table 4

Mean Amplitude Measures (in $\mu \mathrm{V}$; With Standard Errors) At the Three Midline Electrodes in the Early Time Interval for the Old and New Responses in Both Recognition Tasks of Experiment 1

\begin{tabular}{cccccccc}
\hline \multirow{2}{*}{$\begin{array}{c}\text { Response } \\
\text { Type }\end{array}$} & Task & Fz & $S E$ & $\mathrm{Cz}$ & $S E$ & $\mathrm{Pz}$ & $S E$ \\
\cline { 2 - 7 } Old & Object memory & 2.97 & 0.68 & 5.04 & 0.70 & 6.19 & 0.77 \\
& Spatial memory & 3.16 & 0.73 & 6.33 & 0.86 & 7.56 & 0.80 \\
New & Object memory & 1.37 & 0.77 & 3.30 & 0.83 & 5.48 & 0.81 \\
& Spatial memory & 2.44 & 0.83 & 5.21 & 0.89 & 6.06 & 0.89 \\
\hline
\end{tabular}




\section{Method}

\section{Subjects}

Sixteen volunteers ( 10 male) between 21 and 29 years of age (mean, 25 years) participated in this study. All the subjects were students. They had corrected- or corrected-to-normal vision, were right-handed, and were paid $12 \mathrm{DM} / \mathrm{h}$. None of them had participated in Experiment 1.

\section{Stimuli and Procedure}

The stimuli used in the study and the test phase were the same as those in Experiment 1. The procedure was the same as that in Experiment 1 , with the exception that three different interference tasks were interpolated between the study and the test phases. The verbal interference task was identical to the articulatory suppression task employed in Experiment 1 . In the noninterference task, the subjects were required to fixate a cross presented in the middle of the computer screen. In the visual interference task, 2 two-dimensional patterns consisting of four unconnected squares (sidelines, $1 \mathrm{~cm}$ ) were presented successively. After the presentation of the second pattern, the subjects had to indicate whether they were identical by saying "yes" or "no." The patterns were presented for $0.75 \mathrm{sec}$ each, with an interstimulus interval (ISI) of $2.25 \mathrm{sec}$. "Yes" and "no" answers were equiprobable. In order to enable adequate temporal characteristics for presentation times and response times in the visual interference task, the interference tasks' durations were increased from $3 \mathrm{sec}$ in Experiment 1 to $5.5 \mathrm{sec}$ in Experiment 2.

The experiment consisted of 90 study-test trials. Task order, as well as order of interference task, was randomized within the 90 study-test trials, and each of the six combinations of recognition task $X$ interference task was presented 15 times. Thus, there were 60 old and new responses for each of the six task combinations. The subjects performed 12 practice study-test trials ( 2 for each task combination) at the beginning of the session.

\section{Data Analysis}

Performance was examined by means of corrected recognition scores (i.e., hit rate - false alarm rate) for each of the six task combinations.

\section{Results}

All the subjects were highly accurate (i.e., less than $3 \%$ errors) in the visual interference task. Table 5 presents the proportion of correct old and new responses and the corrected recognition scores for both tasks separately for each of the three interference tasks. Comparable with Experiment 1, the subjects made more errors for object- based than for spatial-based recognition judgments. When the verbal interference task was performed between the study and the test phases, the corrected recognition scores decreased relative to the noninterference task by $2.8 \%$ and $3 \%$ in the object and the spatial recognition tasks, respectively. For the conditions including the visual interference task, the corresponding performance decrements relative to the noninterference task were $5.8 \%$ (object recognition) and 5.7\% (spatial recognition). An ANOVA, with recognition task and interference task as factors, performed for the corrected recognition scores revealed main effects of recognition task $[F(1,15)=21.82, p<.004]$ and interference task $[F(2,30)=8.64, p<.004]$ but no interaction among the two factors $(F<1)$. Differences among the noninterference and each of the other two interference tasks were assessed by means of confidence intervals calculated for the corrected recognition scores in the two contrasted conditions (Loftus \& Masson, 1994). These analyses revealed that object task performance was lower in the visual interference condition than in the noninterference conditions, whereas performance in the verbal interference and the noninterference conditions was not significantly different. In the spatial recognition task, performance was lower in the visual and the verbal interference tasks than in the noninterference task. However, this performance decrement was more pronounced in the visual interference task.

\section{Discussion}

In Experiment 2, the disruptive effects of a visual and a verbal interference task, relative to a noninterference task, on recognition judgments for object forms and object locations were examined. The results indicate that recognition performance for both object forms and object locations was disrupted to a larger extent by a visual interference task than by a verbal interference task. The absence of differential interference effects (i.e., larger interference effects in the verbal interference condition on object form judgments and larger interference effects in the visual interference condition on object location judgments) provides strong evidence against the view

Table 5

Recognition Performance (With Standard Errors) for Both Tasks in Each of the Three Interference Conditions of Experiment 2

\begin{tabular}{lcccccccc}
\hline & \multicolumn{9}{c}{$\%$ Correct } & & & \\
\cline { 2 - 6 } \multicolumn{1}{c}{ Task } & Old & $S E$ & New & $S E$ & CR & $S E$ & $\mathrm{CI}_{\mathbf{a}}$ & $\mathrm{CI}_{\mathbf{b}}$ \\
\hline Object memory & & & & & & & & \\
$\quad$ Noninterference & 88.7 & 2.0 & 89.2 & 1.8 & 77.9 & 3.5 & 2.0 & 1.4 \\
$\quad$ Verbal interference & 86.8 & 2.3 & 88.3 & 2.1 & 75.1 & 3.3 & 2.0 & \\
$\quad$ Visual interference & 84.6 & 2.2 & 87.5 & 2.0 & 72.1 & 3.8 & & 1.4 \\
Spatial memory & & & & & & & & \\
$\quad$ Noninterference & 94.1 & 2.1 & 95.8 & 1.4 & 89.9 & 3.5 & 0.8 & 0.3 \\
$\quad$ Verbal interference & 92.6 & 2.3 & 94.4 & 1.8 & 86.9 & 3.9 & 0.8 & \\
$\quad$ Visual interference & 91.4 & 1.5 & 92.8 & 1.7 & 84.2 & 3.1 & & 0.3 \\
\hline
\end{tabular}

Note-CR, corrected recognition; $\mathrm{Cl}$, confidence intervals plotted for the contrasts of interest--that is, $\mathrm{Cl}_{\mathrm{a}}$, noninterference vs. verbal interference; $\mathrm{CI}_{\mathrm{b}}$, noninterference vs. visual interference. 
that verbal labels were used to rehearse object forms but not object locations. The results rather support the view that visual rehearsal mechanisms were used to maintain object forms and object locations in working memory in the interval between the study and the test phases. In light of these results, it can be concluded that differences in performance and ERP measures found in Experiment 1 do not reflect the differential involvement of verbal memory representations for the rehearsal of object forms.

Even though, in light of Experiment 2, selective verbal rehearsal of object forms appears to be unlikely, it is still conceivable that the two tasks differ along other dimensions than the type of information to be retrievedfor instance, the difficulty of the recognition judgments. In light of the differential performance results of Experiment 1, the task-specific ERP old/new effects could thus be related to differences in the accessibility of memorystored information, with more readily accessible information being correlated with posteriorly distributed old/ new effects and more difficult-to-access information being associated with more anteriorly distributed old/new effects. This issue was addressed in Experiment 3.

\section{EXPERIMENT 3}

In order to show that ERP old/new effects reflect differences in the retrieval of object forms and object location per se, rather than differences between easy and difficult recognition judgments, Experiment 3 employed a modified spatial recognition task in which object locations were more difficult to recognize. In this modified spatial task, the subjects were required to make recognition judgments with respect to mirror images of the spatial locations presented during study. We assumed that, if the topographical dissociations in the ERP old/new effects reflect the activation of different brain systems mediating the retrieval of object forms and object locations, these effects should also be present under conditions in which object locations are not easier to recognize than object forms.

\section{Method}

\section{Subjects}

Eighteen volunteers ( 9 male) with a mean age of 25 years (range, 19-34 years) participated in the experiment. All the subjects were students, had correct or corrected-to-normal vision, were righthanded, and were paid $12 \mathrm{DM} / \mathrm{h}$ for their participation. Four of the subjects also participated in Experiment $l$.

\section{Stimuli}

The stimuli (i.e., objects presented at spatial locations within a $4 \times 3$ spatial matrix) were the same as those in Experiment 1 .

\section{Procedure}

The procedure was the same as that in Experiment 1, with the following exceptions. The subjects were again instructed to memorize both the object forms and their respective spatial locations in the study phase. After the articulatory suppression task, one of two 3-letter task cues (SPI vs. OBJ) was presented that indicated that either a spatial or an object recognition memory task had to be per- formed. The object recognition task was the same as that in Experiment 1 , whereas, in the spatial recognition task, the subjects were required to indicate whether the position of a test stimulus was a mirrored position with respect to those positions presented in the study phase. The mirror axis was defined as the vertical midline of the $4 \times 3$ grid. Each test phase included four new locations and four mirrored stimulus locations.

\section{ERP Recording and Data Analysis}

The procedures for EEG recording and data analyses were the same as those in Experiment 1.

\section{Results}

\section{Behavioral Data}

The bottom part of Table 1 shows the performance results for the object and the spatial memory tasks. Response times and accuracy were highly similar in the two tasks. Moreover, for both tasks, old responses were faster than new responses, and both responses were given with the same accuracy. Two-way repeated measures ANOVAs, with task and response type as factors, did not reveal effects of task, either for reaction times $[F(1,17)=0.13$, $p<.72]$ or for accuracy $[F(1,17)=2.64, p<.12]$. A main effect of response type was found for reaction times $[F(1,17)=19.25, p<.001]$ but not for accuracy $[F(1,17)=0.01, p<.93]$. No interactions of task and response type were found for reaction times or accuracy. ${ }^{7}$

\section{Event-Related Potentials}

Anticipation phase. Figure 6 shows that the task cues indicating the object or the spatial memory task, similar to Experiment 1 , evoked rather different patterns of ERP activity. The object task cue evoked larger P300 activity than did the spatial task cue. This observation was confirmed by a significant main effects of task $[F(1,17)=$ $11.78, p<.003]$ in an ANOVA, with task (2 levels) and electrode (19 levels) as factors, performed for mean amplitude measures in the $\mathrm{P} 300$ time interval (i.e., 0.4$0.6 \mathrm{sec}$ ). Following the $\mathrm{P} 300$, for the spatial task cue, more pronounced negative slow wave activity was observed, starting around $0.7 \mathrm{sec}$, with largest betweentask differences emerging at the parietal and occipital recording sites. In contrast to Experiment 1, this pattern was also present, although less pronounced, at the central recording sites. Moreover, no between-task slow wave differences were obtained at the frontal recording sites. These observations translated into the following statistical results: The MANOVA, with task, electrode, and time interval ( 5 levels) as factors, revealed marginally significant main effects of task $[F(1,17)=4.3, p<.053]$ and time interval $[F(4,68)=3.39, p<.056]$ and interactions of task and electrode $[F(18,306)=2.03, p<.05]$ and of task, electrode, and time interval $[F(72,1224)=1.47$, $p<.007]$. The results of the ANOVAs performed separately for each of the five time intervals are displayed in the bottom part of Table 2 .

There were main effects of task in the $1-1.25 \mathrm{sec}$ interval and marginally significant effects in the three intervals from 1.25 to $2 \mathrm{sec}$. The task and electrode factors 


\section{Anticipation phase}
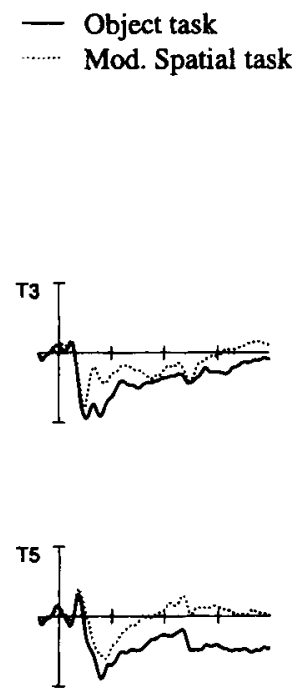
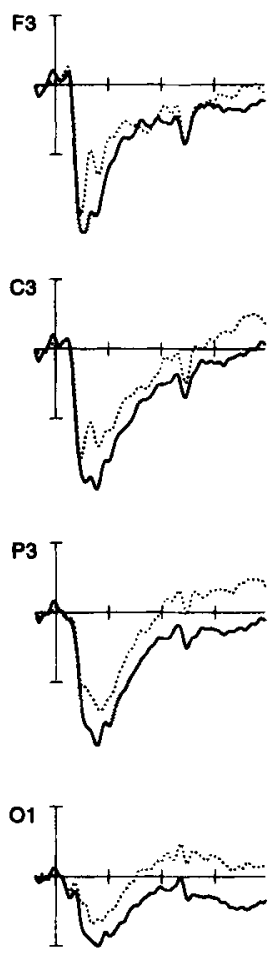
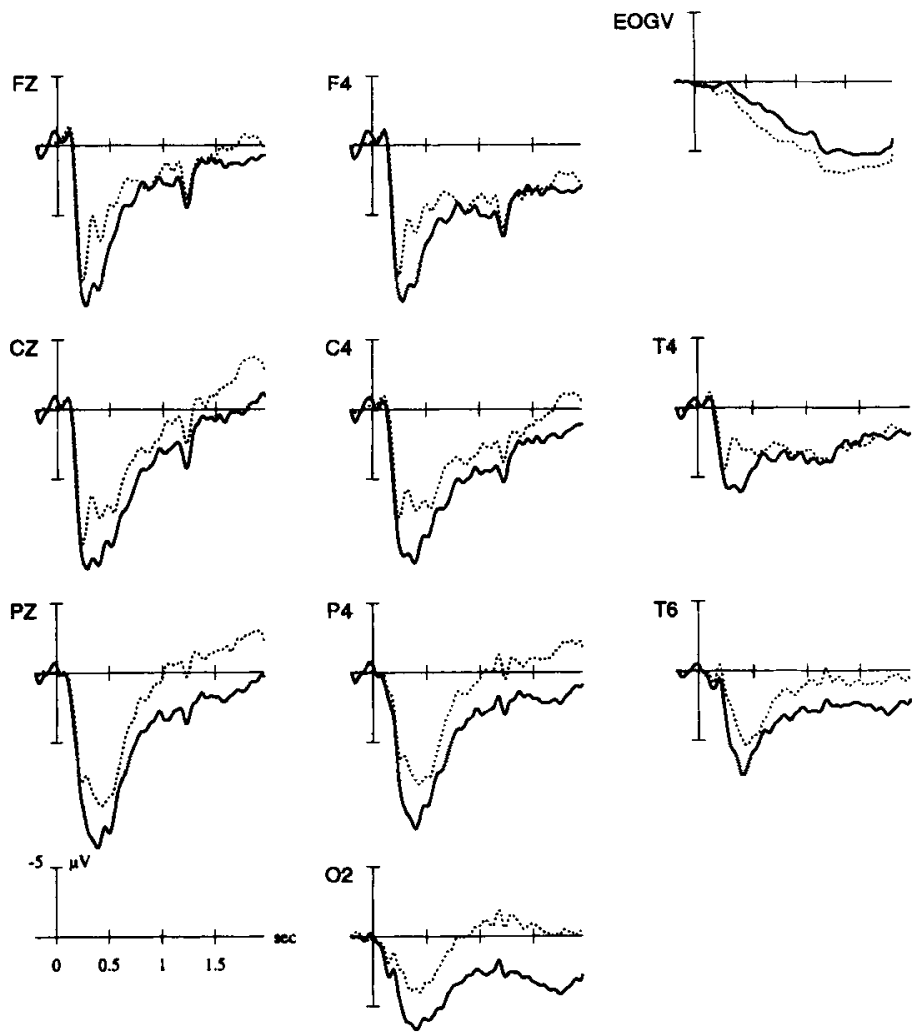

Figure 6. ERP waveforms, averaged across subjects, elicited by the task cues indicating the object or the modified spatial recognition memory task of Experiment 3.

interacted in the two intervals from 1.25 to $1.75 \mathrm{sec}$ and were marginally significant from 1.75 to $2 \mathrm{sec}$. When separate ANOVAs, with task as the factor, were performed for frontal (F3, Fz, and F4) and parietal-occipital electrodes ( $\mathrm{P} 3, \mathrm{Pz}, \mathrm{P} 4, \mathrm{O} 1$, and $\mathrm{O} 2)$, slow wave activity was found to be more negative at the parietal-occipital electrodes in the spatial task in the time range from 1 to $2 \mathrm{sec}$ $(p s<.01)$, whereas no task effects were found for the frontal electrodes.

Old/new effects for object forms and object locations. The ERP waveform evoked by old and new responses in both tasks are displayed in Figures 7 and 8 . In showing anteriorly focused old/new effects during object recognition, starting at about $0.3 \mathrm{sec}$ and extending throughout the recording epoch, the results for this task, as expected, replicate those found for the identical task in Experiment 1. In the spatial task, the early old/new effects were smaller than in the object task and restricted to a smaller time range. On the basis of this latter observation, a smaller time window (i.e., $0.3-0.45 \mathrm{msec}$ ) was used for the quantification of the spatial old/new effects. Similar to Experiment 1 , in this early time interval, the largest old/new effects were obtained at the parietal recordings. Moreover, in the late 1.2-1.8 sec time interval, old/new differences emerged at the frontal recordings, being slightly larger at the right than at the left recording site (i.e., F4 vs. F3). These observations were again confirmed by statistical analyses. ${ }^{8}$ The results of the two-way ANOVAs for each time interval are displayed in the bottom part of Table 3. Similar to Experiment 1, in the object task, there were significant effects of response type and interactions of response type and electrode in the early and late time intervals, whereas, in the middle time interval, only the interaction of response type and electrode reached the significance level. In the spatial task, an effect of response type and a marginally significant response type $\times$ electrode interaction were found only in the first time interval.

To further examine the response type $\times$ electrode interactions, separate ANOVAs for frontal and parietaloccipital electrodes were performed for both tasks. For the object task, the old/new effects were significant in the three time intervals at the frontal recordings $(p s<.05)$, whereas, similar to Experiment 1, these effects did not reach the significance level at the parietal-occipital recordings in the middle and the late time intervals ( $p s>.15)$. An exception to this pattern of results was a significant old/new effect in the 0.3-0.6 sec interval at the posterior recordings for the object task $(p<.02)$; however, as is apparent from Figure $5 \mathrm{~b}$, which presents the estimated effect strengths $\left(\omega^{2}\right)$ for all time intervals, the strength of this latter effect is smaller $\left(\omega^{2}=.15\right)$ than the frontal 
Test phase: Object memory
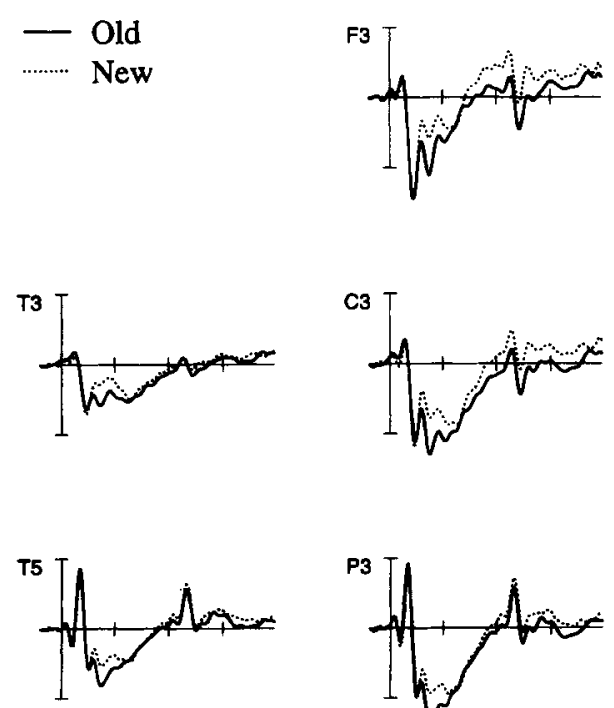
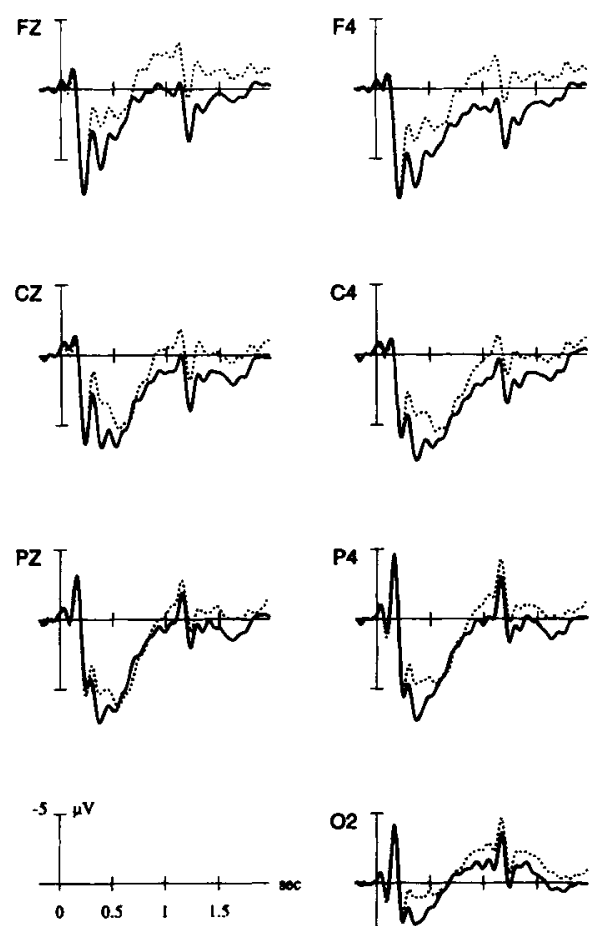
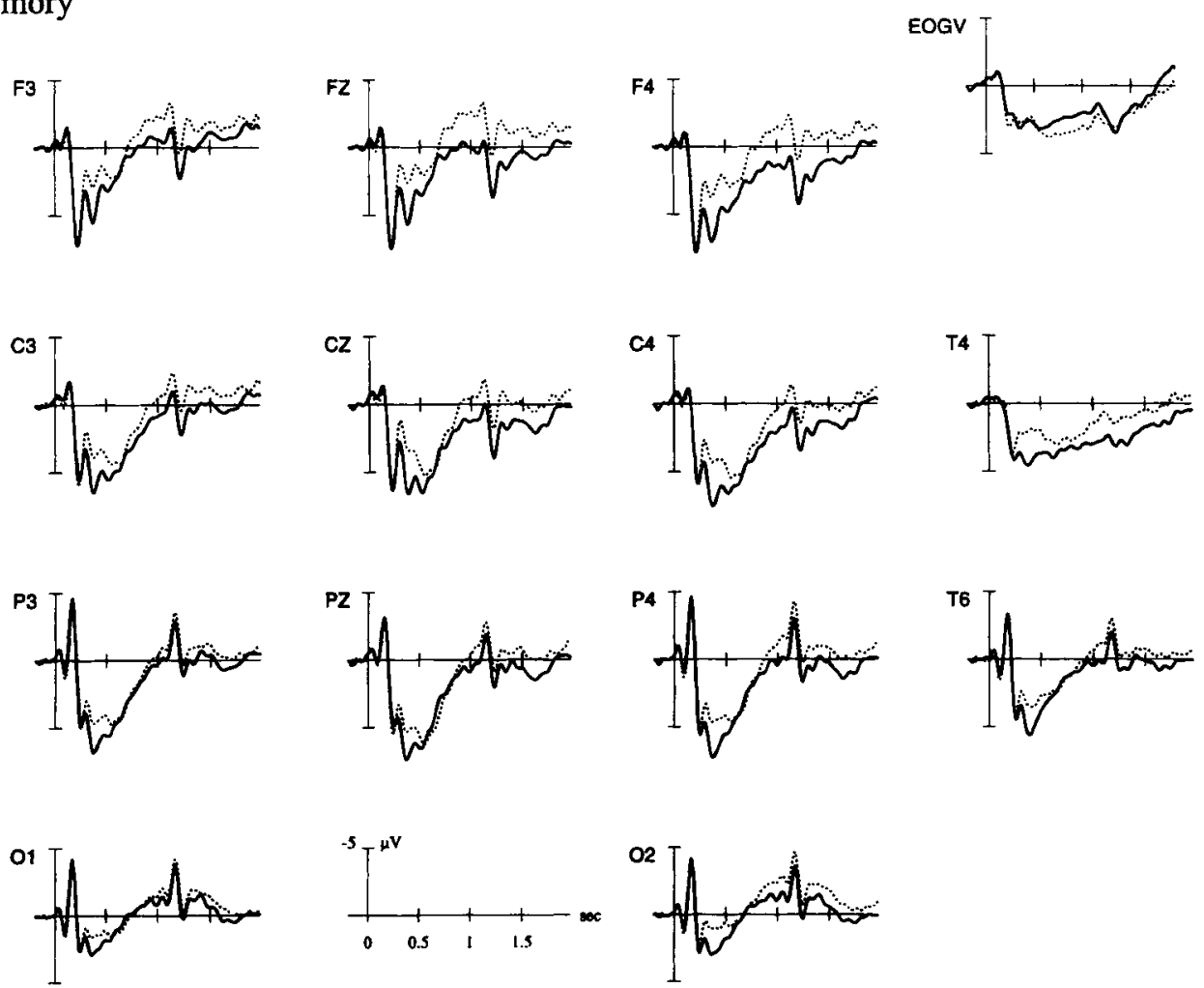

Figure 7. ERP waveforms, averaged across subjects, elicited by old and new responses in the test phase of the object recognition memory task of Experiment 3.

old $/$ new effect in this time interval $\left(\right.$ omega $\left.^{2}=.22\right)$. For the spatial task, old/new effects were statistically reliable only at the parietal-occipital electrodes in the early (i.e., $0.3-.45 \mathrm{sec})$ time interval $(p<.03)$ and at the frontal electrodes in the $1.2-1.8 \mathrm{sec}$ time interval $(p<.05)$.

Lateralization of the old/new differences was again examined by means of pairwise comparisons of lateral electrodes. For the object task, old/new effects were larger at the right frontal (i.e., F4) than at the left frontal recording (i.e., F3) in the middle and the late time intervals $(p s<.05)$. Similar to Experiment 1 , in the late time interval, these effects reflect the fact that the waveforms evoked by old objects were more positive at the right than at the left frontal recording $(p<.01)$, whereas, for new objects, no hemispherical differences were obtained in this time interval $(p>.15)$. For the spatial task, pairwise comparisons of old/new differences did not reveal reliable hemispherical effects. However, post hoc analyses indicate that, in the late time interval, old/new effects were reliable at the right frontal recording $(p<.03)$, but not at the corresponding left frontal electrode $(p>.20)$.

Topographical analyses. In parallel to Experiment 1 , topographical profile analyses were performed to examine the extent to which the scalp-recorded old/new differences in both tasks were mediated by different combinations of neuronal structures. In light of the smaller time range of the spatial old/new effects, this analysis con- trasted the early old/new effects in the $0.3-0.45 \mathrm{sec}$ time interval (spatial task) and in the $0.3-0.6 \mathrm{sec}$ interval (object task). The ANOVA, with task and electrode as factors, performed for the early old/new differences revealed reliable task $\times$ electrode interactions for the raw data $[F(18,306)=1.94, p<.05]$, and the normalized data $[F(18,306)=1.84, p<.05]$, suggesting that the old/new effects of both tasks in this time interval indeed arise from different neuronal structures. However, for the other two time intervals, no reliable interactions between the task and electrode factors were obtained for the raw and normalized data, allowing no inferences about the neuronal generators of these effects in these time intervals. ${ }^{9}$

\section{Discussion}

In this experiment, the retrieval of object forms and object locations from working memory under conditions yielding comparable performance in both tasks was examined. The analysis of performance measures shows that there were no significant between-task differences in reaction times and accuracy when recognition judgments were based on mirror locations of the spatial positions presented in the study phase. For the ERP data, similarities with and differences from Experiment 1 were obtained. Similar to Experiment 1, the task cues indicating the object or spatial recognition tasks evoked more pronounced negative slow wave activity for the spatial than 
Test phase: Mod. spatial memory
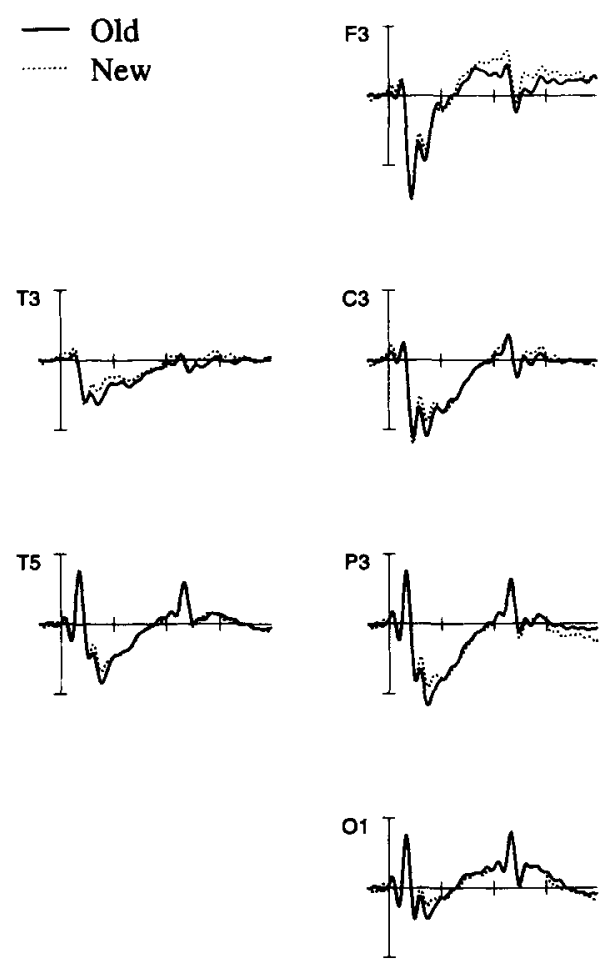
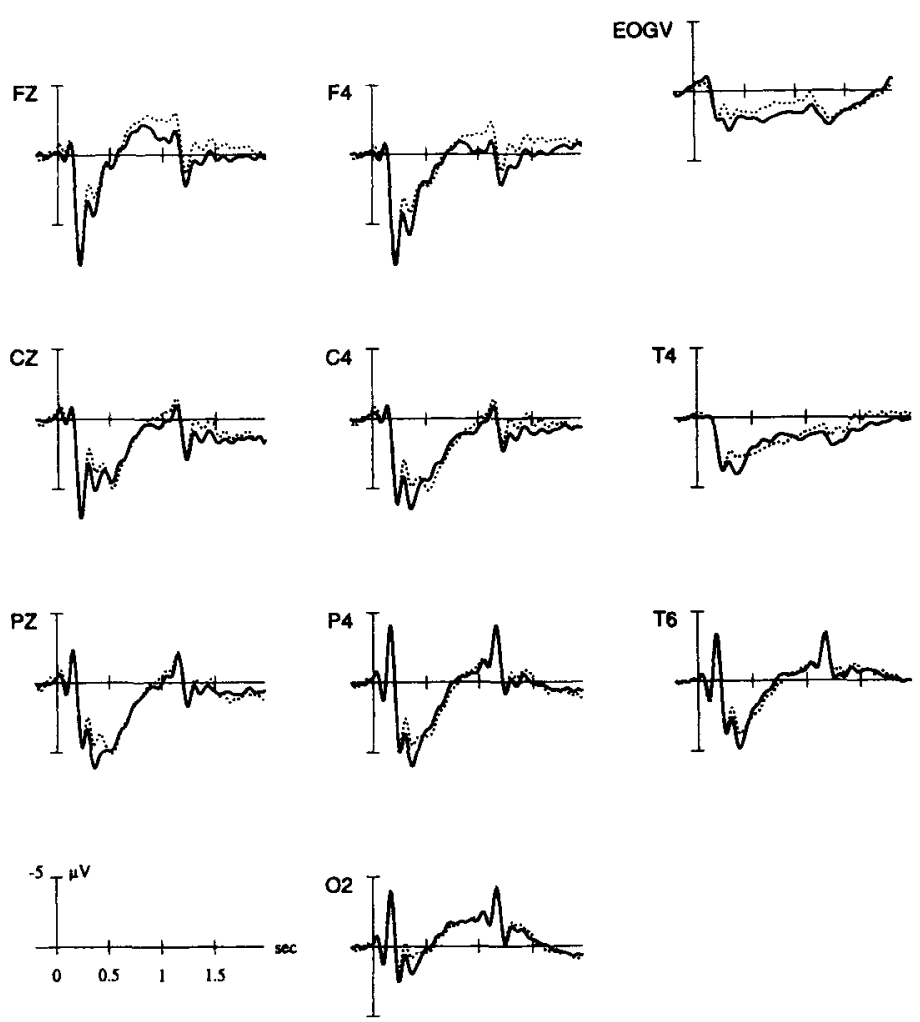

Figure 8. ERP waveforms, averaged across subjects, elicited by old and new responses in the test phase of the modified spatial recognition memory task of Experiment 3.

for the object task at the parietal-occipital electrodes, starting around $1 \mathrm{sec}$ after cue onset. This between-task difference in slow wave activity was larger and more widely distributed over the scalp than the corresponding difference in Experiment 1, so that between-task differences also emerged at the central recordings. Moreover, contrary to Experiment 1, at the frontal recording sites, no task-related slow wave effects were found. An explanation for this differential pattern of results could be that the increased spatial-processing demands in Experiment 3 , imposed by the additional spatial transformation and the rehearsal of the transformed locations, was associated with larger and more widely distributed negative slow wave activity (extending to frontal electrodes), as compared with Experiment 1, that wiped out any frontally located task differences. Support for this view can be derived from a comparison of $\mathrm{P} 300$ amplitudes evoked by the task cues in both experiments. Whereas in Experiment 1, smaller spatial task P300s tended to emerge only at those parietal electrodes at which subsequent negative slow waves were most pronounced (i.e., $\mathrm{Pz}$ and $\mathrm{P4}$ ), in Experiment 3, the P300s to the spatial task cues were smaller than those to the object task cues at all electrode sites. Thus, it is conceivable that these widespread reductions of the spatial task cue P300 result from component overlap with the more pronounced and widely distributed negative slow waves. This latter phenomenon also might have led to an elimination of the frontally focused betweentask difference in slow wave amplitude.

For the ERPs evoked by the test stimuli, topographical between-task differences of the old/new effects were obtained that resemble those found in Experiment 1. The results in the object task replicated those found in the identical object task of Experiment 1. For the spatial task, the old/new effects, although smaller in magnitude, were highly similar in scalp distribution to those observed in the spatial task in Experiment 1 - that is, they were focused to the parietal electrodes in the early time interval and to the right frontal recording site in the late time interval. However, the early old/new effects were restricted to a smaller time window and were of considerably smaller magnitude at the parietal-occipital electrodes $\left(\omega^{2}=.17\right)$ than the corresponding effects in Experiment $1\left(\omega^{2}=\right.$ $.63)$. This latter result might reflect the fact that less information is retrieved from the study phase for spatially transformed locations, as compared with the exact replications of the study-phase locations in Experiment 1. Prior to the general discussion of the results, the differential ERP patterns obtained in Experiments 1 and 3 merit some consideration.

The only difference between the two spatial tasks was the requirement to compare mirror transformations of the studied object locations (Experiment 3 ) rather than the object locations themselves (Experiment 1). In prin- 

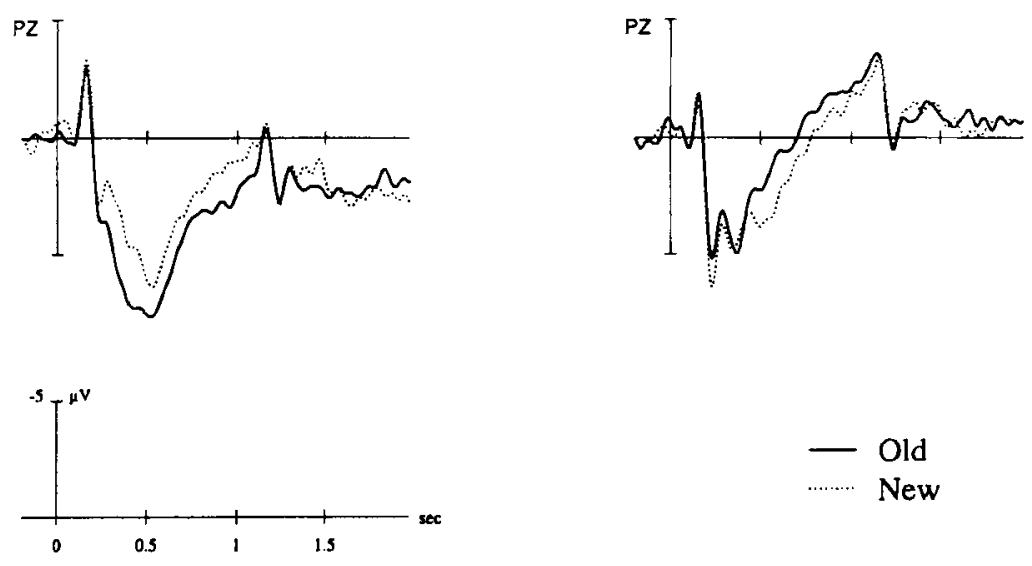

Figure 9. ERP waveforms, averaged across subjects, in the early (left panel) and the late (right panel) transformation group, elicited by old and new responses in the test phase of the modified spatial recognition memory task of Experiment 3.

ciple, two strategies are conceivable for performing the spatial task in Experiment 3: Either the subjects could make the spatial transformations early - that is, in the interval after presentation of the task cue - or they could delay this transformation and transform the object locations upon presentation of the test items.

In order to examine the extent to which subjects used either strategy, and in light of previous studies that indicate that parietally focused negative slow waves are associated with spatial working memory processes, we assumed that early spatial transformations (i.e., those in the anticipation interval) should be reflected by large parietal negative slow waves to the spatial task cue. For subjects showing this pattern, we assumed that there should be no additional processing load in the test phases caused by the necessity to make spatial transformations. Consequently, we predicted that the old/new effects of these subjects should resemble those obtained in Experiment 1.

To test this prediction, a median split of the subject group was performed. The 9 subjects showing large negative slow waves to the spatial task cue, relative to the object task cue, at the parietal electrodes (P3, Pz, and P4) in the time intervals in which these differences were largest (i.e., 1-2 sec; cf. Figure 6) were contrasted with those subjects showing small slow wave differences in this time interval. By operational definition, these two groups will be labeled early and late transformation groups, respectively. Notably, both groups of subjects showed highly similar recognition performance in both tasks, so that reaction times and error rates were not significantly different between the object and the spatial task, either for the early or for the late transformation group $(F \mathrm{~S}<1)$.

The old/new effects in the spatial task of Experiment 3 for both groups of subjects are presented in Figure 9. The early transformation group showed large old/new effects in the time range from 0.3 to $1 \mathrm{sec}$, whereas, for the late transformation group, the corresponding effects were absent or even negative in polarity. ${ }^{10} \mathrm{As}$ is apparent from
Figure 10, which presents the estimated effect strength of the old/new effects for the early transformation group, the magnitudes of the old/new effects in the spatial task are highly similar to those obtained in Experiment 1 (cf. Figure 5), especially in the first and second time interval. In parallel to Experiment 1, we also examined the relative contribution of both response types to the task-specific scalp topography of the early old/new effects in the early transformation group. As is apparent from Table 6 and from statistical analyses, there was a significant task $\times$ electrode interaction for new responses $[F(2,16)=5.07$, $p<.01]$, which reflects the fact that new objects evoked smaller (i.e., more negative) ERP responses at the frontal and central electrodes but not at the parietal electrode. Although, for old responses, the mean amplitude measures appear to be larger in the spatial task, the task $\times$ electrode interaction did not reach the significance level $[F(2,16)=1.48, p<.25]$.

Taken together, this post hoc analysis provides support for the view that the smaller magnitudes of the spatial old/new effects in Experiment 3 to some extent result from differential performance strategies employed for location-based recognition judgments in Experiment 3. When data analyses were restricted to those subjects showing large parietal slow wave differences in the anticipation phase, who presumably make the mirror transformation in this phase of the task, both the magnitude and the topographic distribution of the old/new effects were highly similar to those obtained in Experiment 1. Notably, this group of subjects also shows highly similar patterns of performance in both recognition tasks.

\section{GENERAL DISCUSSION}

The results of the present experiments provide several lines of evidence for the view that object forms and object locations are separately rehearsed in and retrieved from working memory. In Experiment 1, better perfor- 


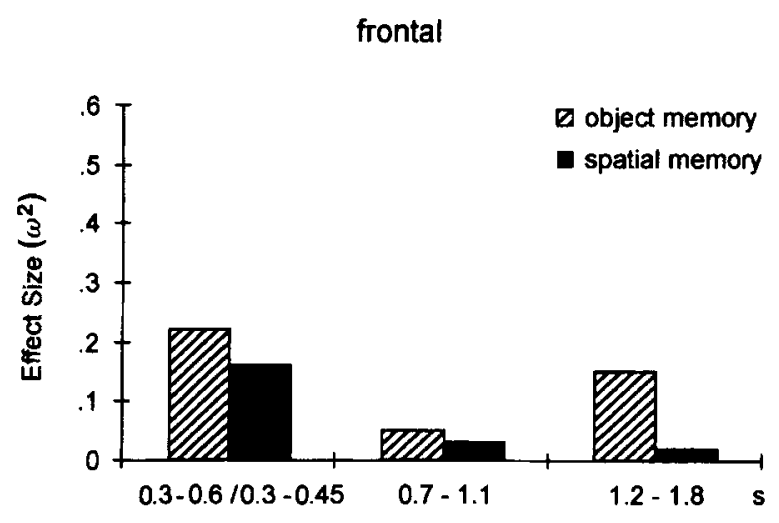

parietal - occipital

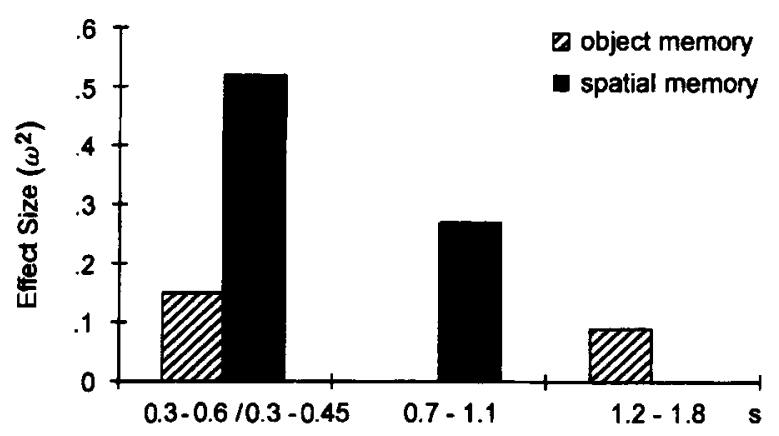

Figure 10. Strength of effect $\left(\omega^{2}\right)$ of the response type manipulations in both recognition tasks at the frontal (F3, Fz, and F4) and parietal-occipital (P3, Pz, P4, O1, and O2) electrodes for the early transformation group in Experiment 3.

mance results were obtained when recognition judgments were based on spatial locations than when they were based on object forms. Moreover, old/new differences with wide temporal and task-specific topographical distributions were found for both recognition tasks. In the early time interval, these effects were anteriorly focused in the object task and posteriorly focused in the spatial task. For the later time intervals (i.e., after $0.7 \mathrm{sec}$ ) for both tasks, pronounced old/new differences were evident at the right frontal recordings. In showing significant interference effects for a visual but not for a verbal secondary task interpolated between the study and the test phases, Experiment 2 supports the view that rehearsal of both object locations and object forms was based on visual representations in working memory. In Experiment 3 , the question of whether the topographically different old/new effects reflect differences between easy and difficult recognition judgments or, rather, functionally different retrieval operations for object forms and object locations was examined. Task performance was highly similar for object-based and location-based recognition judgments, and some of the topographic features of the old/new effects in Experiment 1 were replicated. Again, in the early time interval, the old/new differences in the spatial task were posteriorly focused, and those in the object task were most pronounced at the frontal recordings; in the late time interval, these effects yielded a right frontal maximum in both recognition tasks. However, as compared with Experiment 1, the early old/new effects in the spatial task were restricted to a smaller time window and were of smaller magnitude. In light of these latter results, a post hoc analysis was performed in which two groups of subjects were contrasted. For those subjects presumed to make the required mirror transformation in the anticipation phase and for which, consequently, less additional spatial processing in the test phases can be assumed, the magnitude of the spatial old/new effects was highly similar to that in Experiment 1. This finding might suggest that the reduced spatial old/new effects in Experiment 3 result from the additional processing load in the test phases. It must be noted, however, that the above-mentioned post hoc analysis relies on a variety of assumptions that cannot be confirmed with the data at hand. For instance, it is assumed that the subjects use either strategy consistently throughout all experimental trials and that mirror transformations in the test phase lead to increases in spatial processing load that are associated with reduced old/new effects. Although the magnitude of old/new differences has been reported to correlate with the amount of information retrieved from a prior study episode (see Rugg et al., 1995), this only provides tentative support for the assumption of an additional spatial-processing load causing attenuated old/new effects in the spatial task of Experiment 3. From this it follows that, unless further experimentation has not confirmed the validity of the above-mentioned assumptions, our conclusions with respect to retrieval operations for spatial information are tentative. With these considerations in mind, we will now discuss the functional significance of the various ERP effects.

\section{The Anticipation Phase: Rehearsal of Object and Spatial Stimulus Features}

Parietal maximal negative slow wave activity similar to the slow wave activity evoked by the spatial task cue has consistently been reported in tasks requiring the retention of visuospatial materials in working memory, such as imaging spatial maps (Uhl, Goldenberg, et al., 1990) or memorizing or transforming spatial configurations (Heil et al., 1996; Mecklinger \& Müller, 1996; Peronnet

Table 6

Mean Amplitude Measures (in $\mu V$; With Standard Errors) at the Three Midline Electrodes in the Early Time Interval for the Old and New Responses of the

Early Transformation Group of Experiment 3

\begin{tabular}{llcccccc}
\hline \multirow{2}{*}{$\begin{array}{l}\text { Response } \\
\text { Type }\end{array}$} & Task & Fz & $S E$ & $\mathrm{Cz}$ & $S E$ & $\mathrm{Pz}$ & $S E$ \\
\cline { 3 - 8 } Old & Object memory & 3.66 & 2.13 & 5.21 & 2.30 & 7.05 & 2.33 \\
& Spatial memory & 4.08 & 2.13 & 6.20 & 2.43 & 7.22 & 2.38 \\
New & Object memory & 1.16 & 1.70 & 2.50 & 1.69 & 4.82 & 1.95 \\
& Spatial memory & 2.71 & 1.97 & 4.23 & 2.29 & 4.82 & 2.55 \\
\hline
\end{tabular}


\& Farah, 1989; Ruchkin, Canoune, Johnson, \& Ritter, 1995; Ruchkin et al., 1992). Consistent with these studies, posterior negative slow wave activity in the present experiments emerged when working memory operations with spatial materials--that is, rehearsal of the four study locations (Experiment 1) and mirror transformations and rehearsal of the transformed locations (Experiment 3)were required. Pronounced bilateral negative slow waves at frontal recording, similar to those observed in the anticipation interval of the object task relative to the spatial task, have been found in tasks in which figural materials had to be retained in working memory (Mecklinger \& Pfeifer, 1996; Uhl, Lang, Lang, Kornhuber, \& Deecke, 1990).

It has been argued that negative slow waves reflect increased neuronal activity in restricted neocortical layers close to the electrode sites at which they are recorded (Birbaumer et al., 1990; Somjen, 1973). Thus, the relative differences in the slow wave pattern might suggest that parietal-occipital brain areas, which also constitute the dorsal pathway involved in perceptual processing of spatial information (Ungerleider \& Haxby, 1994) are relatively more engaged in spatial than in object working memory processes. Conversely, frontal brain regions might be more engaged in object memory processes. It must be noted, however, that these conclusions are constrained by the fact that ERP slow wave activity could only be assessed as relative differences between the two conditions and thus cannot unambiguously be interpreted as negative slow waves evoked by either task cue. Consequently, although ERP activity in the anticipation phase was clearly dissociable, we cannot say with certainty which functional processes they reflect and by which brain regions they are generated. Further experiments-for instance, one including a baseline anticipation phase without working memory requirements - are necessary to further delineate the functional significance of ERP slow wave activity in visual working memory tasks.

\section{The Test Phase: Retrieval of Object and Spatial Stimulus Features}

Early time interval. Old/new effects for both types of recognition judgments emerged in the early (i.e., P300) time interval and in later time intervals during and after the behavioral responses. It has repeatedly been argued that the larger P300s for old responses result from differences in the target detection process between old and new responses, so that the $\mathrm{P} 300$ reflects encountering the match in general rather than processes directly linked to the recognition process (cf. Neville et al., 1986). However, the finding of topographical differences of the old/ new effects evoked in the object and spatial recognition tasks in the $\mathrm{P} 300$ interval provides strong evidence against that view.

Johnson (1995) proposed that parietally focused P300 components in recognition memory paradigms reflect the strength or discriminability of a memory trace during retrieval. In support of this hypothesis, Johnson, Pfefferbaum, and Kopell (1985) found a close relation- ship between the magnitude of the parietal P300 and the hit rates during recognition. Moreover, only the parietal P300 was found to increase with the number of correctly classified items. Consistent with this view, in Experiment 1 , the waveforms in the P300 interval were more positive at the central and parietal but not at the frontal recording site for the easier-to-perform spatial task (cf. Table 4). Moreover, for the early transformation group of Experiment 3, for which recognition performance was virtually identical in both tasks, no between-task differences were obtained for the early time interval of the waveforms evoked by old responses (cf. Table 6). These findings are consistent with the view that the parietal P300 is associated with the strength or accessibility of memory representations during recognition.

The analysis of between-task differences also offers an explanation for the topographic dissociation of the early old/new effects evoked by the two tasks. In both experiments, new objects evoked more negative-going ERPs than did new spatial locations in the $0.3-0.6$-sec time interval, with these effects being most pronounced at frontal and central recordings. It has repeatedly been found that, similar to words, pictorial stimuli that are inconsistent with a preceding context evoke N400-like components (Barrett \& Rugg, 1990; Ganis, Kutas, \& Sereno, 1996). Although it is still a matter of debate whether pictures and words access the same or different semantic systems (cf. Glaser, 1992), N400s evoked by pictures, unlike N400s evoked by written words, are consistently found to be larger at frontal than at parietal recording sites. Given this, it is conceivable that objects, unlike spatial locations, are subjected to semantic processing (i.e., accessing the pictures' meanings) and that this is reflected by a frontocentrally distributed N400 component to new objects, whose modulations underlie the early old/new effects in the object but not in the spatial task. In this framework it is conceivable that the parietal maximal distribution of the old/new differences during location-based judgments at least to some extent arose from the absence of conceptual semantic processing and is more likely to reflect an increased parietally distributed positivity associated with the retrieval of structural representations of spatial locations.

Late time intervals. In the later time intervals (i.e., after $0.7 \mathrm{sec}$ ), pronounced old $/$ new differences emerged in both tasks at the right frontal recordings. Interestingly, besides being smaller in the spatial task than in the object task, these effects were also evident earlier for the faster location-based judgments in Experiment 1 than in the modified spatial task that was associated with longer responses. These late old/new effects bear some similarities to ERP results from a recent study on memory for source by Wilding and Rugg (1996). The authors found a right frontal positive slow wave that was still present at around $1,400 \mathrm{msec}$ after the onset of the to-be-recognized words. Since it was larger for correctly classified old words, for which correct source judgments also were made, it is assumed that this component is associated 
with the retrieval of context information from the study episode. Similar to the Wilding and Rugg findings, the late object-based old/new effects show hemispherical differences, with old objects evoking a more pronounced positive slow wave at right than at left frontal recordings. In view of these similarities, it is tempting to speculate that the late right frontal effects reported by Wilding and Rugg and those found in the present experiments may index the same functions, such as the recollection of contextual information from the study episode (i.e., in the present experiments, the spatial or temporal position of the objects). Thus, a reasonable but still tentative explanation for the late right frontal old/new effects might be that they are associated with the recovery of context information or with some type of control processes that operate on the products of the retrieval process. This latter notion is also supported by recent functional-imaging studies that have shown that the prefrontal cortex, especially in the right hemisphere, covaried with the proportion of correctly retrieved words in a recognition memory task (Rugg, Fletcher, Frith, Frackowiak, \& Dolan, 1996) or in tasks that require the retrieval of episodic memory information (Buckner, 1996; Nyberg, Cabeza, \& Tulving, 1996). However, further experimentation is required to get a more detailed picture of the nature of the cognitive activity associated with late old/new ERP differences over the right frontal cortex.

In conclusion, the results add to the converging evidence that, similar to the disparity in the perceptual processing of object and spatial information, there are dissociable systems for retrieving object and spatial information from visual working memory. Evidence for functionally dissociable retrieval systems for object forms and object locations was provided by the topographic dissociations of the early old/new effects during object-based and spatialbased recognition judgments. This dissociation was obtained when studied spatial locations had to be recognized (Experiment 1) and, although less discernible, when recognition judgments were required for mirror transformations of the studied locations (Experiment 3 ). This pattern of results can be taken as evidence that different brain regions are involved in retrieving object forms and spatial locations from working memory. From a functional point of view, the results are consistent with the view that object recognition involves access and retrieval of conceptual semantic information, whereas recognition memory for object locations relies on structural representations of spatial information. Further research delineating the functional characteristics of visual working memory processes as well as the brain regions mediating these processes remains an important endeavor.

\section{REFERENCES}

Atkinson, R. C., \& Shiffrin, R. M. (1968). Human memory: A proposed system and its control processes. In K. W. Spence \& J. T. Spence (Eds.). The psychology of learning and motivation: Advances in research and theory (Vol. 2, pp. 89-105). New York: Academic Press.
BadDEley, A. D. (1986). Working memory (Oxford Psychology Series No. 11), Cambridge: MRC Applied Psychology Unit.

BADDELEY, A. D. (1990). Working memory. Science, 255, 556-559.

BADDELEY, A. D., \& LiebermaN, K. (1980). Spatial working memory. In R. Nickerson (Ed.), Attention and performance VIII (pp. 521-539). Hillsdale, NJ: Erlbaum.

BARRETT, S. E., \& RugG, M. D. (1990). Event-related potential and the phonological matching of pictures. Brain \& Language, 38, 424-437.

Barrett, S. E., RugG, M. D., \& Perrett, D. I. (1988). Event-related potentials and the matching of familiar and unfamiliar faces. Neuropsychologia, 26, 105-117.

Birbaumer, N., Elbert, T., Canavan, A. G. M., \& Rockstroh, B. (1990). Slow potentials of the cerebral cortex and behavior. Physiological Review, 70, 1-41.

BUCKNER. R. L. (1996). Beyond HERA: Contributions of specific prefrontal brain areas to long-term memory retrieval. Psychonomic Bulletin \& Review, 3, 149-158.

CoHEN, J. (1977). Statistical power analyses for the behavioral sciences. New York: Academic Press.

DANEMAN, M., \& TARDIF, T. (1987). Working memory and reading skill reexamined. In M. Coltheart (Ed.), Attention and performance XII: The psychology of reading (pp. 491-508), Hove, U.K.: Erlbaum

ERIKSEN, B. A., Eriksen, C. H., \& HofFMan, J. E. (1986). Recognition memory and attentional selection: Serial scanning is not enough. Journal of Experimental Psychology, 12, 476-483.

FARAH, M. J. (1988). Is visual imagery really visual? Overlooked evidence from neuropsychology. Psychological Review, 95, 307-317.

Farah, M. J., Hammond, K. M., Levine, D. N., \& Calvanio, R. (1988). Visual and spatial mental imagery: Dissociable systems of representations. Cognitive Psychology, 20, 439-462.

FrIEDERICI, A. D. (1993). On places, prepositions, and other relations Behavioral \& Brain Sciences, 16, 245-246.

Friedman, D., \& SutTon, S. (1987). Event-related potentials during continuous recognition memory. In R. Johnson, Jr., J. W. Rohrbaugh, \& R. Parasuraman (Eds.), Current trends in event-related potential research (EEG Suppl. 40, pp. 316-321). Amsterdam: Elsevier.

Ganis, G., Kutas, M., \& Sereno, M. I. (1996). The search for "common sense": An electrophysiological study of the comprehension of words and pictures in reading. Journal of Cognitive Neuroscience, 8 , 89-106.

GeIsSer, S., \& Greenhouse, S. (1959). On methods in the analysis of profile data. Psychometrika, 24, 95-112.

Gevins, A., Cutillo, B., \& SMith, M. E. (1995). Regional modulation of high resolution evoked potentials during verbal and non-verbal matching tasks. Electroencephalography \& Clinical Neurophysiology, 94, 129-147.

Glaser, W. R. (1992). Picture naming. Cognition, 42, 1-3, 61-106.

Goodale, M. A., \& Milner, A. D. (1992). Separate visual pathways for perception and action. Trends in Neurosciences, 15, 20-25.

Heil, M., Rösler, F., \& Hennighausen, E. (1996). Topographically distinct cortical activation in episodic long-term memory: The retrieval of spatial versus verbal information. Memory \& Cognition, 24, 777-795.

Hillyard, S. A., \& KuTAS, M. (1983). Electrophysiology of cognitive processing. Annual Review of Psychology, 34, 33-61.

INGLE, D. (1993). Evolution and physiology of "what" versus "where." Behavioral \& Brain Sciences, 16, 247-248.

JoHNSON, R., JR. (1993). On the neuronal generators of the P300 component of the event-related potential. Psychophysiology, 30, 90-97.

JoHNSON, R., JR. (1995). Event-related potential insights into the neurobiology of memory systems. In R. Johnson, Jr., \& J. C. Baron (Eds.), Handbook of neuropsychology (Vol. 10, pp. 135-164). Amsterdam: Elsevier.

Johnson, R., JR., Pfefferbaum, A., \& Kopell, B. S. (1985). P300 and long term memory: Latency predicts recognition performance. Psychophysiology, 22, 497-507.

Karis, D., Fabiani, M., \& Donchin, E. (1984). "P300” and memory: Individual differences in the von Restorff effect. Cognitive Psychologv, 16, 177-216. 
KEPPEL, G. (1991). Design and analysis. Englewood Cliffs, NJ: PrenticeHall.

Kramer, A. F, \& Strayer, D. L. (1988). Assessing the development of automatic processing: An application of dual-task and event-related brain potential methodologies. Biological Psychology, 26, 231-267.

LANDAU, B., \& JACKENDOFF, R. (1993). "What" and "where" in spatial language and spatial cognition. Behavioral \& Brain Sciences, 16 , 217-238.

LANDAU, B., \& STECKER, D. (1990). Objects and places: Syntactic and geometric representations in early lexical learning. Cognitive Development, 5, 287-312.

LoFTUS, G. R., \& MASSON, M. E. J. (1994). Using confidence intervals in within-subject designs. Psychonomic Bulletin \& Review, 4, 476-490.

LOGIE, R. H., \& MARCHETTI, C. (1991). Visuo-spatial working memory: Visual, spatial or central executive? In R. H. Logie \& M. Denis (Eds.), Mental images in human cognition (pp. 105-115). Amsterdam Elsevier.

MCCARTHY, G., \& WoOD, C. C. (1985). Scalp distribution of eventrelated potentials: An ambiguity associated with analysis of variance models. Electroencephalography \& Clinical Neurophysiology, 62, 203-208.

Mecklinger, A., Kramer, A. F., \& Strayer, D. L. (1992). Event related potentials and EEG components in a semantic memory search task. Psychophysiology, 29, 104-119.

Mecklinger, A., \& MüLleR, N. (1996). Dissociations in the processing of "what" and "where" information in working memory: An event-related potential analysis. Journal of Cognitive Neuroscience, 8, 453-473.

MeCKLINGer, A., \& Pfeifer, E. (1996). Event related potentials reveal topographical and temporal distinct neuronal activation patterns for spatial and object working memory. Cognitive Brain Research, 4 211-224.

Neville, H., Kutas, M., Chesney, G., \& Schmidt, A. L. (1986). Event-related potentials during initial encoding and recognition of congruous and incongruous words. Journal of Memory \& Language, 25, 75-92.

NEwCOMBE, F., RatClifF, G., \& DaMasio, H. (1987). Dissociable visual and spatial impairments following right posterior cerebral lesions Clinical, neuropsychological and anatomical evidence. Neuropsychologia, 18, 149-161.

Nyberg, L., Cabeza, R., \& Tulving, E. (1996). PET studies of encoding and retrieval: The HERA model. Psychonomic Bulletin $\& R e$ view, 3, 135-148.

OKEN, B. S., \& ChIAPPA, K. H. (1986). Statistical issues concerning computerized analysis of brainwave topography. Annals of Neurology, 19, 493-494

PAller, K. A., \& KUTAS, M. (1992). Brain potentials during memory retrieval provide neurophysiological support for the distinction between conscious recollection and priming. Journal of Cognitive Neuroscience, 4, 375-391.

Paller, K. A., Kutas, M., \& McIsaac, H. K. (1995), Monitoring conscious recollection via the electrical activity of the brain. Psychological Science, 6, 107-111.

Peronnet, F., \& Farah, M. J. (1989). Mental rotation: An ERP study with a validated mental rotation task. In M. Kutas \& B. Renault (Eds.), Proceedings of the 4th International Conference on Cognitive Neuroscience (pp. 49-52). Paris: Dourdan.

Posner, M. I., \& Raichle, M. E. (1994). Images of the mind. New York: Scientific American.

RICHARDSON, J. T. E. (1996). Measures of effect size. Behavior Research Methods, Instruments, \& Computers, 28, 12-22.

Rösler, F., Heil, M. \& Hennighausen, E. (1995). Distinct cortical activation patterns during long-term memory retrieval of verbal, spatial, and color information. Journal of Cognitive Neuroscience, 7 , $51-65$.

Ruchion, D. S., Canoune, H. L., Johnson, R., JR., \& Ritter, W. (1995). Working memory and preparation elicit different patterns of slow wave event-related potentials. Psychophysiology, 32, 399-410.

Ruchkin, D. S., Johnson, R., JR., Grafman, J., Canoune, H., \& RitTER, W. (1992). Distinctions and similarities among working mem- ory processes: An event-related potential study. Cognitive Brain Research, 1, 53-66.

RUGG, M. D. (1995). Event-related potential studies of human memory. In M. S. Gazzaniga (Ed.), The cognitive neurosciences (pp. 789-802). Boston: MIT Press.

RugG, M. D., Cox, C. J. C., Doyle, M. C., \& Wells, T. (1995). Eventrelated potentials and the recollection of low and high frequency words. Neuropsychologia, 33, 471-484

RugG, M. D., Fletcher, P. C., Frith, C. D., Frackowiak, R. S. J., \& Dol.AN, R. J. (1996). Differential activation of the prefrontal cortex in successful and unsuccessful memory retrieval. Brain, 119, 2073-2083.

RugG, M. D., Furda, J., \& LoRist, M. (1988). The effects of task on the modulation of event-related potentials by word repetition. Psychophysiology, 25, 55-63.

Smith, E. E., Jonides, J., Koeppe, R. A., Awh, E., Schumacher, E. H., \& Minoshima, S. (1995). Spatial versus object working memory: PET investigations. Journal of Cognitive Neuroscience, 7, 337-356.

Sмiтн, M. E. (1993). Neurophysiological manifestations of recollection experience during recognition memory judgements. Journal of Cognitive Neuroscience, 5, 1-13.

SMITH, M. E., \& HALGREN, E. (1989). Dissociations of recognition memory components following temporal lobe lesions. Journal of $E x$ perimental Psychology: Learning. Memory, \& Cognition, 15, 50-60.

SOM IEN, G. G. (1973). Electrogenesis of sustained potentials. Progress in Neurobiology, 1, 199-237.

Tresch, M. C., Sinnamon, H. M., \& Seamon, J. G. (1993). Double dissociation of spatial and object visual memory: Evidence from selective interference in intact human subjects. Neuropsychologia, 31, 211-219.

Uhl, F., Goldenderg, G., LANG, W., Lindinger, G., STeiner, M., \& DEECKE, L. (1990). Cerebral correlates of imaging colours, faces and a map. II: Negative cortical DC potentials. Neuropsychologia, 28, 81-93.

Uhl, F., Lang, W., Lang, M., Kornhuber, A., \& Deecke, L. (1990). DC potential evidence for bilateral symmetrical frontal activation in non-verbal associative learning. Journal of Psychophysiology, 4, 241-248.

UNGERLEIDER, L. G., \& HAXBY, J. V. (1994). "What" and "where" in the human brain. Current Opinion in Neurobiology, 4, 157-165.

UNGERLEIDER, L. G., \& MISHKIN, M. (1982). Two cortical visual systems In D. J. Ingle, M. A. Goodale, \& R. J. W. Mansfield (Eds.), Analysis of visual behavior (pp. 549-586). Cambridge, MA: MIT Press.

van Essen, D., ANDerson, C., \& Felleman, D. (1992). Information processing in the primate visual system: An integrated systems perspective. Science, 255, 419-423.

WILDING, E. L., \& RUGG, M. D. (1996). An event-related potential study of recognition memory with and without retrieval of source. Brain, $119,889-905$

\section{NOTES}

1. The $p$ value for the task effect for CR scores was $p<.001$.

2. Since each test phase included four old and four new items, it is conceivable that the subjects were able to guess correctly to a larger extent for late test items, yielding better recognition performance for these items than for early test items. To address this issue, error rates were examined separately for the first and the second half of the test phases This analysis revealed that the error rates (collapsed across old and new responses) sightly increased from $11.4 \%$ to $14.1 \%$ in the spatial task but did not differ between the first (22.5\%) and the second half $(22.3 \%)$ of the object recognition test phases. This pattern of results indicates that recognition performance was not different for the first and second half of the test phases and thus rules out the possibility that correct guesses were more likely on later test items than on early test items

Performance measures were also examined separately for old and new objects presented at previously studied and unstudied positions and for old and new spatial positions filled with previously studied and unstudied objects. In the object recognition task, the mean values for re action time and percent errors (in parentheses) were $784 \mathrm{msec}(22.0 \%)$ and $778 \mathrm{msec}(24.3 \%)$ for old objects presented at previously studied and unstudied positions, respectively. The corresponding values for new objects presented at studied and unstudied positions were $827 \mathrm{msec}$ 
$(21.8 \%)$ and $819 \mathrm{msec}(21.6 \%)$, respectively. In the spatial recognition task, performance for old positions filled with previously studied and unstudied objects was $664 \mathrm{msec}(16.6 \%)$ and $660 \mathrm{msec}(15.2 \%)$, respectively. For new responses, the corresponding values for new positions filled with studied and unstudied objects were $698 \mathrm{msec}(10.2 \%)$ and $707 \mathrm{msec}(9.3 \%)$, respectively. None of these differences was statistically reliable $\left(F_{\mathrm{S}}<1\right)$.

3. Figure 2 suggests that, at the parietal electrodes, the object task cue evoked slightly larger $\mathrm{P} 300$ than the cue indicating location-based judgments. An ANOVA, with task (2) and electrode (19) factors, performed for the mean amplitude measures in the 400-600-msec time interval did not reveal reliable effects of task or task $\times$ electrode interaction $(F \mathrm{~s}<1)$. At the Pz electrode, however, the between-task difference was marginally significant $[F(1,15)=3.29, p<.08]$.

4 . For the object task, the global MANOVAs, with response type (2 levels), electrode ( 19 levels), and time interval ( 3 levels) as factors, revealed significant main effects of response type $[F(1,15)=9.79, p<$ $.006]$ and time interval $[F(2,30)=6.32, p<.01]$ and interactions of response type and electrode $[F(18,270)=4.78, p<.001]$ and of time interval and electrode $[F(36,540)=6.14, p<.001]$. The same analyses performed for the spatial task revealed main effects of response type $[F(1,15)=17.71, p<.0008]$ and time interval $[F(2,30)=12.93, p<$ $.0001]$ and interactions of response type and electrode $[F(18,270)=5.30$ $p<.001]$ and of time interval and electrode $[F(36,540)=6.05, p<.001]$

5 . Omega ${ }^{2}$ is a relative measure of treatment magnitude, reflecting the proportional amount of the total population variance that can be attributed to the variations among the experimental treatments. The index can range from 0 to 1 , and, according to Cohen (1977), an effect is considered large if it produces an omega ${ }^{2}$ of .15 or greater.

6 . The same ANOVAs also were performed for the three midline electrodes. These analyses revealed significant task $\times$ electrode interactions for the old/new differences in all three time intervals $[F(2,30)=$ $10.72-46.22, p s<.001]$. For the normalized data, significant interactions were obtained in all three time intervals as well $(p s<.001)$.
7. The $p$ value for the task effect for CR scores was $p<.14$ in Experiment 3 .

8. For the object task, the global MANOVA, with response type, electrode, and time interval as factors, revealed main effects of time interval $[F(2,34)=25.13, p<.001]$ and response type $[F(1,17)=5.60, p<.03]$ and the following interactions: response type $\times$ electrode $[F(18,306)=$ $3.85, p<.001]$, time interval $\times$ electrode $[F(36,612)=5.22, p<.002]$, and time interval $\times$ response type $[F(3,51)=3.67, p<.05]$. When the same analysis was performed for the spatial task, main effects of time interval $[F(2,34)=23.39, p<.001]$, marginally significant effects of response type $[F(1,17)=4.07, p<.059]$, and a significant time inter$\mathrm{val} \times$ response type $\times$ electrode interaction $[F(36,612)=2.78, p<.01]$ were obtained.

9. Highly similar results were obtained when ANOVAs, with task and electrode as factors, were performed for the old/new differences at the midline electrodes in Experiment 3 . For the early old/new effects, there were task $\times$ electrode interactions for the raw data $[F(2,34)=4.54, p<$ $.02]$ and the normalized data $[F(2,34)=3.73, p<.04]$, whereas no statistically significant interactions were obtained for the raw and normalized data in the middle and late time intervals $(p s>.15)$.

10 . These observations were quantified using the early $(0.3-0.6 \mathrm{sec})$, middle, and late time intervals of the ERP waveforms. For the early transformation group, the three-way ANOVA, with response type ( 2 levels), electrode ( 19 levels), and time interval ( 3 levels) as factors, revealed main effects of time interval $[F(2,16)=10.31, p<.01]$ and marginally significant effects of response type $[F(1,8)=4.10, p<.07]$ Moreover, there was a significant interaction of response type and time interval $[F(2,16)=4.48, p<.02]$. In contrast, for the late transformation group, neither a main effect of response type nor any significant interaction involving this factor was obtained $(p s>.20)$.

(Manuscript received February 28, 1996; revision accepted for publication July 15,1997 .) 